\title{
Psychological Factors Associated with Development of TMD: the OPPERA Prospective Cohort Study
}

\author{
Roger B. Fillingim ${ }^{1}$, Richard Ohrbach ${ }^{2}$, Joel D. Greenspan ${ }^{3}$, Charles Knott ${ }^{4}$, Luda \\ Diatchenko $^{5,7}$, Ronald Dubner ${ }^{3}$, Eric Bair ${ }^{5,6,7}$, Cristina Baraian ${ }^{6}$, Nicole Mack ${ }^{6}$, Gary D. \\ Slade $^{5,8}$, and William Maixner ${ }^{5,7}$ \\ ${ }^{1}$ University of Florida, College of Dentistry, and Pain Research and Intervention Center of \\ Excellence \\ ${ }^{2}$ Department of Oral Diagnostic Sciences, University at Buffalo \\ ${ }^{3}$ Department of Neural and Pain Sciences, and Brotman Facial Pain Center, University of \\ Maryland School of Dentistry \\ ${ }^{4}$ Battelle Memorial Institute, Center for Analytics and Public Health \\ ${ }^{5}$ Center for Neurosensory Disorders, University of North Carolina at Chapel Hill \\ ${ }^{6}$ Department of Biostatistics, University of North Carolina at Chapel Hill \\ ${ }^{7}$ Department of Endodontics, University of North Carolina at Chapel Hill \\ ${ }^{8}$ Department of Dental Ecology and Department of Epidemiology, University of North Carolina at \\ Chapel Hill
}

\section{Abstract}

Case-control studies have consistently associated psychological factors with chronic pain in general and with temporomandibular disorders (TMD) specifically. However, only a handful of prospective studies has explored whether pre-existing psychological characteristics represent risk factors for first-onset TMD. The current findings derive from the prospective cohort study of the Orofacial Pain Prospective Evaluation and Risk Assessment (OPPERA) cooperative agreement. For this study, 3,263 TMD-free participants completed a battery of psychological instruments assessing general psychological adjustment and personality, affective distress, psychosocial stress, somatic symptoms, and pain coping and catastrophizing. Study participants were then followed prospectively for an average of 2.8 years to ascertain cases of first-onset of TMD, and 2,737 provided follow-up data and were considered in the analyses of TMD onset. In bivariate and demographically-adjusted analyses, several psychological variables predicted increased risk of first-onset TMD, including reported somatic symptoms, psychosocial stress, and affective distress. Principal component analysis of 26 psychological scores was used to identify latent constructs, revealing four components: stress and negative affectivity, global psychological and somatic

\footnotetext{
(C) 2013 The American Pain Society. Published by Elsevier Inc. All rights reserved

${ }^{1}$ Please address all correspondence to: Roger B. Fillingim, Ph.D., University of Florida College of Dentistry, 1329 SW 16th Street, Room 5180, PO Box 103628, Gainesville, FL 32610-3628, Phone: (352) 273-5963, Fax: (352) 273-5985, rfilling@ ufl.edu.

Publisher's Disclaimer: This is a PDF file of an unedited manuscript that has been accepted for publication. As a service to our customers we are providing this early version of the manuscript. The manuscript will undergo copyediting, typesetting, and review of the resulting proof before it is published in its final citable form. Please note that during the production process errors may be discovered which could affect the content, and all legal disclaimers that apply to the journal pertain.

Disclosures

Richard Ohrbach, Joel Greenspan, Charles Knott, Ronald Dubner, Eric Bair, Nicole Mack and Cristina Baraian declare that they have no conflicts of interest.
} 
symptoms, passive pain coping, and active pain coping. In multivariable analyses, global psychological and somatic symptoms emerged as the most robust risk factor for incident TMD. These findings provide evidence that measures of psychological functioning can predict first-onset of TMD. Future analyses in the OPPERA cohort will determine whether these psychological factors interact with other variables to increase risk for TMD onset and persistence.

\section{Keywords}

temporomandibular disorders; psychological risk factors; chronic pain; somatic symptoms; psychosocial stress

\section{Introduction}

The association of psychological factors with clinical pain has been well documented. Numerous cross-sectional studies demonstrate that people with chronic pain conditions show greater levels of psychological distress, environmental stress, catastrophizing, and somatic symptoms compared with pain-free controls. ${ }^{19,34,42}$ Temporomandibular disorders (TMD) represent a group of orofacial pain conditions that are highly prevalent in the population and are associated with considerable morbidity. ${ }^{20,21,41}$ Similar to the above findings, in other chronic pain conditions, people with chronic TMD pain exhibit greater psychological maladjustment, on average, compared to healthy controls ${ }^{23,73}$. For example, in studies conducted in the U.S. and Europe, people with chronic TMD reported higher mean levels of affective distress, somatic awareness, psychosocial stress, and pain catastrophizing than pain-free individuals. ${ }^{11,30,54,57,70}$ In other cross-sectional studies, personality characteristics, such as neuroticism, differed for chronic TMD cases versus controls. ${ }^{29,66}$ Related findings are that psychological dysfunction is associated with greater severity and persistence of TMD-related clinical symptoms. For example, in cross-sectional studies, scores on measures of psychological distress were positively correlated with reported TMD pain and pain-related disability. ${ }^{9,57,90}$ Further, in studies involving patients with existing TMD, psychological factors, such as somatic symptoms and depression, predict long-term persistence of TMD pain. ${ }^{25,33,61}$

Because the preceding associations were observed in studies of people with existing TMD, they do not establish whether psychological factors were premorbid risk factors for the development of TMD. In a precursor to the present study, Slade and colleagues ${ }^{81}$ showed that several psychological factors associated with experimental pain sensitivity, including depression, perceived stress, and mood state, predicted new onset TMD pain in a cohort of females followed over a three-year period. Subsequently, Aggarwal et $\mathrm{al}^{2}$ reported that baseline levels of health anxiety (i.e. concern regarding bodily symptoms), predicted risk for development of chronic orofacial pain over the following two-year period. More recently, depression and anxiety were found to predict new onset of TMD-related joint and muscle pain, respectively ${ }^{44}$. Thus, the limited available data from prospective studies implicate psychological variables as potential etiologic risk factors for TMD.

The Orofacial Pain: Prospective Evaluation and Risk Assessment (OPPERA) prospective cohort study endeavors to discover etiologic influences on TMD pain. While previous research has identified multiple psychological variables that confer increased risk for development of chronic pain, few studies have incorporated a broad-based assessment of psychological functioning in order to identify risk factors for development of TMD. To overcome this potential limitation, OPPERA administered an extensive battery of psychological instruments to a cohort who did not have TMD when enrolled in the study. The goal was to assess psychological functioning, prior to onset of TMD, across several 
domains that previously were associated with chronic pain, including TMD. We recently reported psychological findings from the OPPERA baseline case-control study, in which a cohort of participants meeting diagnostic criteria for chronic TMD were compared to a control cohort comprised of individuals who did not have TMD. ${ }^{30,78}$ Chronic TMD cases reported higher levels of psychological symptoms, affective distress, somatic symptoms, and pain catastrophizing compared to TMD-free controls.

Below we present findings from the OPPERA prospective cohort study in which people who initially were found not to have TMD when examined were followed for up to 5.2 years in order to detect first-onset TMD. The primary aim of this study was to identify psychological characteristics at enrollment that were associated with development of first-onset TMD. A secondary aim of the study was to explore the extent to which psychological variables interact with demographic factors as well as with other psychological variables in predicting risk for TMD onset.

\section{Materials and Methods}

Institutional review boards at each study site approved study procedures and participants provided signed, informed consent. Full details of enrollment, follow-up and statistical analyses are provided elsewhere in this volume ${ }^{79}$ and are summarized here.

\section{Recruitment, Eligibility Criteria and Enrollment}

This paper reports findings from the OPPERA prospective cohort study of 2,737 people who were enrolled in 2006-08 and followed for up to 5.2 years in order to identify those who developed temporomandibular disorder (TMD). OPPERA used advertisements, emails, flyers and word-of-mouth to recruit participants between May 2006 and November 2008 from communities in and around academic health centers at four US study sites: Baltimore, MD; Buffalo, NY; Chapel Hill, NC; and Gainesville, FL. When they were enrolled, the sample of community-based volunteers at four study U.S. sites was aged 18-44 years and did not have painful TMD when examined using Research Diagnostic Criteria for TMD (RDC/TMD). ${ }^{21}$ The average age of the sample was 27.1 years $(\mathrm{SD}=7.8)$, and the sample was comprised of 1630 women $(59.6 \%)$ and 1448 non-Hispanic whites (52.9\%), 766 African Americans (28\%), and 523 (19.1\%) participants from other ethnic/racial groups. At enrollment, study participants also completed questionnaires, autonomic function and sensitivity to sensory stimuli were evaluated, and a blood sample was collected for genotyping. This paper focuses on contributions of baseline measurements of psychological functioning (i.e., those recorded at enrollment) to subsequent risk of developing TMD. Additional methodological detail is available elsewhere in this volume. ${ }^{79}$

\section{Psychological Instruments}

In order to strike a balance between thoroughness and participant burden, the selection of psychological instruments for the OPPERA Study was based on the following criteria: 1) we emphasized constructs identified in the previously proposed OPPERA heuristic model, including mood/affect, stress, somatic symptoms ${ }^{16,56} ; 2$ ) we prioritized constructs previously associated with TMD in either case-control or prospective studies; and 3) we endeavored to include constructs assessing both general psychological function (e.g. personality, psychological symptoms) and more specific pain-related constructs (e.g. pain coping, somatic symptoms). The psychological questionnaires administered are described below. For all instruments, participants had the option to complete the questionnaire via paper form or electronic PDF version. Through self-selection, slightly more than one-third of participants (ranged from $36.2 \%$ to $39.5 \%$ depending on the questionnaire) completed the instruments via paper and just under two-thirds completed them electronically, and mode of 
administration had minimal effect on any of the reported outcomes. To distribute participant burden, most of the questionnaires were completed before the baseline clinic visit (preclinic), while state-based measures (the State Anxiety Inventory and the Profile of Mood States-Bipolar) were completed in-clinic immediately before the baseline clinical examination. Missing questionnaire items were imputed using the expectation-maximization (EM) algorithm as described previously. ${ }^{30}$ In general, if a subject skipped at least one but less than half the items in a questionnaire, the missing items were imputed. If they failed to complete at least half of the items in the questionnaire, we treated their summary score as missing.

\section{Global Measures of Psychological Function}

Symptom Checklist 90-Revised (SCL90R)-This 90-item instrument evaluates a broad range of psychological symptoms by having participants report the extent to which they have been bothered by each symptom on a five-category scale (not at all, a little bit, moderately, quite a bit, extremely). The SCL90R provides measures of psychological distress across the following nine subscales: Somatization, Obsessive-Compulsive, Interpersonal Sensitivity, Depression, Anxiety, Hostility, Phobic Anxiety, Paranoid Ideation, and Psychoticism. ${ }^{16}$ Some evidence suggests a unitary factor structure for the SCL90R, ${ }^{24}$, while other findings indicate a multiple factor structure, overlapping to some extent with the subscales originally reported by Derogatis. ${ }^{65,77}$ Given this mixed evidence and consistent with the preponderance of studies using this instrument to investigate chronic pain, we chose to use the original scoring to optimize comparisons with existing literature. This instrument has demonstrated good internal consistency (Cronbach's alpha for subscales in our sample ranged from 0.78 to 0.88 ) and test-retest reliability, which ranged from 0.78 to $0.90 .{ }^{15}$ The SCL90R has been widely used in research with numerous pain conditions, 3,13,67,69,76 including TMD. ${ }^{43,48,63,87}$

Eysenck Personality Questionnaire-Revised (Short Form, EPQ-R)-This 57-item true-false instrument assesses three personality dimensions: Extraversion, Neuroticism, and Psychoticism. The EPQ-R also includes a Lie scale, which reflects an effort to present oneself in the most positive light. Factor analysis of the EPQ-R supports the four scales, and internal consistency of each of the scales is acceptable, with Cronbach's alpha in our sample ranging from 0.62 to 0.82 , similar to that previously reported for the full scale. ${ }^{28}$ Scales derived from the 57-item EPQ-R Short Form were found to correlate highly with scale scores from the original EPQ-R, with correlation coefficients ranging from 0.89 to $0.96^{27}$. Based on previous research in chronic pain populations, 7,14,38,85 including TMD, 45,46 our analyses focused on the Extraversion and Neuroticism scales.

\section{Measures of Affective Distress}

State-Trait Anxiety Inventory (STAI)-The STAI includes two 20 item questionnaires, the State Anxiety Inventory and the Trait Anxiety Inventory. ${ }^{82}$ For each item, participants are asked to indicate either how they "generally feel" (trait anxiety) or how they "feel right now" (state anxiety) using a four-category scale (not at all, somewhat, moderately so, extremely so). Test-retest reliability for the Trait Anxiety Scale has been adequate, ranging from 0.73 to 0.86 over intervals of 20 to 104 days. ${ }^{82}$ As expected, State Anxiety is significantly less stable over time, given the transitory nature of anxiety states. In our sample, internal consistencies for both scales were high, with Cronbach's alphas of greater than 0.91 .

The Profile of Mood States-Bipolar (POMS-Bi)—This instrument consists of 72 mood-related items, and participants indicate the extent to which each item describes their mood state over the past week, including today, using a four-category scale (much unlike 
this, slightly unlike this, slightly like this, much like this). This questionnaire assesses both positive and negative affective dimensions. It yields six subscale scores (Agreeable-Hostile, Elated-Depressed, Confident-Unsure, Energetic-Tired, Clearheaded-Confused, ComposedAnxious), as well as global indices of Positive Affect and Negative Affect, which were the focus of our analyses. Internal consistency in our sample was high for both Positive Affect (0.91) and Negative Affect (0.94). The POMS has been well validated with other mood measures and is sensitive to subtle differences in affective state. ${ }^{53}$

\section{Measures of Psychosocial Stress}

The Perceived Stress Scale (PSS)—This 10-item scale assesses the perception of stress, that is, the degree to which an individual appraises situations as stressful, and the extent to which an individual perceives themselves capable of coping with the situations ${ }^{12}$. For each item, participants indicate how often they felt or thought that way in the past month using a five-category scale (never, almost never, sometimes, fairly often, very often). The PSS yields a single overall perceived stress score by summing the numerical weights of each item, after reverse scoring four of the items. Internal consistency was good with Cronbach's alpha of 0.86 in our sample, and construct validity has been demonstrated, as the PSS correlates significantly with other measures of stress appraisal. ${ }^{12}$

The Life Experiences Survey (LES)-This 57-item instrument assesses the frequency of life events that have occurred over the past year, as well as the impact of these events ${ }^{75}$. Impact ratings range from -3 (extremely negative) to +3 (extremely positive), with 0 indicating "no impact." There are multiple approaches to scoring the LES, which generally yield measures of frequency of positive, negative, and total events as well as positive, negative, and total impact of events. The test-retest reliability of positive impact was reported as low ( 0.10 and 0.53 across two samples), while reliabilities for negative and total impact were adequate, ranging from 0.56 to 0.88 . Therefore, we report the number and impact of negative events. Cronbach's alpha for the number of negative events in our sample was 0.93 . Previous research indicated that scoring of impact based on individualized weights (i.e., each respondent's rating of impact) was the best predictor of psychological distress ${ }^{91}$; therefore, we report negative impact scores based on individualized weights in the included tables. For the LES, subjects who endorsed 40 or more items were excluded, on the grounds that they likely misunderstood the instructions for the questionnaire. Others were excluded from LES scoring if their answers were inappropriate based on their gender. (For example, male respondents who reported a pregnancy in the previous year were discarded.)

\section{The Lifetime Stressor List/PTSD Checklist-Civilian Version (LSL/PCL-C)—The}

LSL presents a checklist of 15 different traumatic events, and participants indicate which (if any) of these events they have experienced. For participants who endorse at least one item, they are then asked to identify the most significant stressor, and they complete the remaining 17-items regarding the extent to which they experience PTSD symptoms (e.g., repeated, disturbing memories of the experience) related to the selected traumatic event. Each item is endorsed on a five-category scale (not at all, a little bit, moderately, quite a bit, extremely). A total score is derived by summing the scores from each of the 17 symptoms. Test-retest reliability is high (0.96), and internal consistency has ranged from 0.89 to $0.92 .{ }^{88}$ Internal consistency in our sample was 0.93 . For participants who did not endorse any traumatic events, PCL-C scores were set to a minimum score of 17.

\section{Measures of Somatic Symptoms and Reactivity}

People with chronic pain often report multiple somatic symptoms across different bodily systems (e.g. nausea, fatigue, dizziness), and varied terminology has been applied to this phenotypic domain, including somatization, hypochondriasis, hypervigilance, and somatic 
awareness. ${ }^{30,31,59}$ These terms imply underlying cognitive or psychological processes that are not directly assessed in most instruments. Therefore, we use the term "somatic

symptoms," which we believe accurately reflects the construct assessed by the two primary measures included in the OPPERA study, the PILL (described below) and the SCL90R Somatization Scale (described above).

The Pennebaker Inventory of Limbic Languidness (PILL) assesses the frequency with which individuals experience of 54 common physical symptoms and sensations on a five-category scale (never or almost never, less than 3 or 4 times a year, every month or so, every week or so, more than once every week). A single summary score is derived by summing each of the individual item responses, and PILL scores are related to the construct of somatic awareness or the general tendency to endorse physical symptoms. High internal consistency (alpha = 0.88 ) and adequate test-retest reliability ( 0.70 over two months $)^{68}$ have been reported. Internal consistency in our sample was 0.93 . The PILL has been used as a measure of general somatic symptomatology in fibromyalgia patients, who demonstrated higher scores on the PILL compared to arthritis patients and pain-free controls. ${ }^{59}$

The Kohn Reactivity Scale ${ }^{47}$-This instrument consists of 24 items that assess an individual's level of reactivity or central nervous system arousability to sensory stimuli. Individuals respond to each item on a five-category scale ranging from "disagree strongly" to "agree strongly." The Kohn yields a single summary score created by summing all of the items, after reverse scoring half of the items. This measure has been reported to have adequate internal consistency, ranging from alpha of 0.73 to 0.83 in previous studies ${ }^{47}$ and 0.81 in our sample. The Kohn has been shown to correlate negatively with pain tolerance ${ }^{17}$ and it has been used as a measure of the construct of hypervigilance. ${ }^{59}$

\section{Measures of Coping/Catastrophizing}

The Coping Strategies Questionnaire-Revised (CSQ-R)-The CSQ-R is a revised version of the original CSQ, ${ }^{74}$ consisting of 27 items relating to how individuals cope with pain. Participants indicate the frequency with which they engage in specific coping activities when experiencing pain using a seven-category numerical scale, ranging from 0 (never do that) to 6 (always do that). It yields six subscales reflecting the pain coping strategies that individuals use: diverting attention, catastrophizing, praying and hoping, ignoring pain sensations, reinterpreting pain sensations, and coping self-statements. The subscales showed adequate internal consistency, with Cronbach's alpha ranging from 0.82 to 0.92 in our sample. The CSQ-R has been shown to have stable factor structure in people with chronic pain ${ }^{72}$ and in healthy populations. ${ }^{36}$ Because the catastrophizing scale from the CSQ-R is identical to the Helplessness scale from the PCS (see below), the CSQ-R's catastrophizing scale was excluded from all analyses.

The Pain Catastrophizing Scale (PCS)-This instrument consists of 13 items rated on a 5-point scale ranging from 0 (not at all) to 4 (all the time). Participants indicate the degree to which they have specified thoughts and feelings when experiencing pain. The measure assesses three dimensions of catastrophizing: Rumination, Magnification, and Helplessness, and a total score is calculated by summing the three subscales. Internal consistency was very good, with coefficient alphas ranging from 0.74 to 0.91 across subscales in the current sample. The PCS has been validated for both clinical and nonclinical samples. ${ }^{64,84}$ For nonclinical samples, respondents are asked to respond to the questionnaire based on their thoughts when they experience common pain events (e.g. headache, toothache). 


\section{Follow-up and Case-Classification of First-Onset TMD}

At three-monthly intervals after enrollment, study participants were asked to complete questionnaires that screened for TMD pain symptoms. Specifically, participants responded to questions about "headaches or pain in your face, jaw, temples, in front of the ear, or in the ear" (hereafter "orofacial pain") during the reporting period. Those reporting symptoms were contacted by the study site by telephone and/or email and asked to return for an examination that determined presence or absence painful TMD using the same RDC/TMD criteria. Specifically, to be classified as incident cases, study participants had to meet two criteria: (1) symptoms of orofacial pain reported for $\geq 5$ days in the prior 30 days; and (2) examiner findings of TMD myalgia, arthralgia, or both. Of the 3,263 participants enrolled into the inception cohort, 2,737 (84\%) completed one or more quarterly follow-up questionnaires, with a median of 10 follow-up questionnaires over a median 2.8 follow-up year period. Additional details regarding follow-up rates are provided in Bair, et al. ${ }^{5}$

\section{Statistical Analysis}

A multi-stage analytic approach was developed to identify psychological characteristics that predicted TMD onset and to determine which psychological variables interacted with demographic factors and with other psychological variables in predicting risk for TMD onset. As is common in epidemiologic studies of TMD ${ }^{1,46}$, the first stage of analysis examined univariate associations to test which individual psychological variables predicted TMD onset. This univariate approach provides information regarding which individual psychological measures are associated with risk for development of TMD and provides a basis for readers to compare findings across studies using the same variable. The limitation of this approach is that, not surprisingly, some of the individual variables are intercorrelated, and findings from the univariate approach should be interpreted with the knowledge that some of the associations are not independent.

The second stage of the analysis involved a series of multivariable Cox regression models in which the entered psychological variables were derived from a principal component analysis (PCA), which was performed in order to reduce the number of psychological variables by identifying putative latent constructs. The goal of Cox multivariable modeling was to assess independent contributions of each latent construct to TMD incidence. In this context, an "independent" contribution is one which is not confounded by the other latent constructs. Hazard ratios for the associations were estimated in a single Cox regression model that included all latent constructs as predictor variables, together with study site and sociodemographic characteristics. First, all factors were entered into a multivariable Cox regression model simultaneously in order to identify the factors that independently predicted development of TMD. Second, interactions of each factor score with demographic variables in predicting TMD development were examined in Cox regression models. Third, all possible two-way interactions between factor scores were examined in regression models. This more traditional multivariable approach allowed us to examine whether psychological variables, either alone or via interactions with other variables, predicted TMD onset.

The third stage of the analysis involved a different multivariable approach, random forest modeling, to analyze potential contributions of all measured psychological variables, not merely the reduced set of latent constructs. This novel method of data mining was used to achieve two goals: a) to identify the most important risk factors for first-onset TMD; and b) to generate plots depicting adjusted association between each variable and TMD incidence, with adjustment for the effects of other variables and with latitude in generating the plots that permitted departure from a straight-line association. Random forest modeling represents a machine learning technique based on a series of decision tree models. ${ }^{40}$ Decision trees predict outcomes by recursively partitioning predictor variables, and these trees are superior 
to regression-based models in identifying non-linear effects and handling missing data. Random forests improve the accuracy of individual decision trees by averaging over a series of decision trees. In recent years, random forests have been increasingly applied to classification problems in biomedical research, including predicting several pain related outcomes. ${ }^{39,71,89}$ The random forest model computed importance scores for each variable, representing the decrease in the predictive accuracy of the model when the variable is removed from the analysis. The most important variable was assigned a score of 100, and all other importance scores have lower values that could range to a negative value if the variable worsened prediction. The random forest model was used also to compute the expected rate of first-onset TMD that would be observed at several values of the variable after averaging over the values of all other variables in the model. Partial dependence plots were then generated and LOESS smoothing was used to help visualize the association. ${ }^{52}$

The two multivariable strategies were selected in favor of other approaches for several reasons. The first strategy builds on findings from our baseline case-control studies which identified meaningful latent constructs from among the multitude of psychological measures used in OPPERA. ${ }^{30}$ The relatively small number of latent constructs meant that all four of them could be used in a single Cox regression model, thereby adjusting for potential confounding effects between constructs. This avoided arbitrary choices and potential bias that occur commonly when stepwise procedures and related variable selection methods are used to select a restricted set of potential confounders. ${ }^{35}$ However, regression using principal component scores can mask effects on TMD incidence of single items that do not fit will within the latent constructs. Furthermore, it does not provide information about the relative importance of the variables that contribute to each score, and variable selection methods used to exclude variables from a large candidate set of predictors do not provide information about the excluded variables. Also, variable selection regression methods produce $\mathrm{p}$-values and confidence intervals that are unreliable. ${ }^{1,35}$ Thus, a random forest model was used to address these shortcomings. ${ }^{8,40}$ Random forests have other advantages compared to conventional linear regression models. For example, random forests can impute for missing data and handle large numbers of correlated predictor variables without decreasing the accuracy of the model. ${ }^{37}$

For descriptive purposes, the rate of first-onset TMD was calculated as the number of people with first-onset TMD divided by the sum of follow-up periods, and the result was expressed as the percent of people per annum. To test hypotheses about associations between baseline characteristics and the TMD incidence rate, univariate hazard ratios were first computed using Cox proportional hazard regression. For each variable, scores were transformed to unit-normal deviates (mean $=0$, standard deviation $=1$ ), which allows hazard ratios to be compared meaningfully when original psychological scores were computed using different scales. Hazard ratios were computed with adjustment for study site and with additional adjustment for age, gender, race/ethnicity and lifetime US residence. Univariate hazard ratios were also computed using multiple imputation to assess two sources of potential biases associated: a) non-examination of 243 people with symptoms (due to their unwillingness or inability to return to the study site for re-examination, see Bair, et al ${ }^{5}$ for further detail); and b) a higher-than expected rate of TMD classification for one examiner who conducted 75 examinations. Additional details regarding the multiple imputation approach are provided in Bair et al. ${ }^{5}$ Briefly, the multiple imputation procedure used logistic regression to estimate the probability of examiner-verified TMD for all symptomatic episodes that were followed by an examination, excluding examinations conducted by the examiner in question. The parameters from this regression were then applied to symptomatic episodes that were not followed by an examination and to all episodes that were classified by the examiner in question, yielding a predicted probability of first onset TMD for such episodes. 
The variables included in the PCA were selected based on both our previous case-control findings and the OPPERA conceptual model. ${ }^{30}$ For purposes of predicting first-onset TMD, we expanded the variables included in the PCA model in order to insure that all important predictors were represented. All variables in Table 1 were included in the PCA, except for the two LES variables, which were excluded due to high rates of missingness. Consistent with our previous approach ${ }^{30}$, PCA models were fit using the R statistical computing platform. All variables were normalized to have mean 0 and standard deviation 1 prior to fitting the models. Eigenvalues from the initial, unrotated solution were inspected using a scree plot. To help determine the optimal number of eigenvectors, a parallel analysis was performed to determine the number of components that exceeded what would be expected due to chance alone. Parallel analysis estimates the number of components to include in a PCA model by generating random data sets with the same numbers of observations and predictor variables as the original data. ${ }^{86}$ The eigenvalues are computed for each random data set and averaged over all the data sets. When the average eigenvalue from these randomly generated data sets is larger than the corresponding eigenvalue of the original data, then the principal component associated with that eigenvalue is likely to be random noise (see Supplementary e-Figure 1). After calculating the PCA eigenvectors, a promax rotation was applied to increase the interpretability of the resulting PCA loadings. The promax rotation produced loadings that were easier to interpret than the loadings resulting from orthogonal rotations, and other non-orthogonal rotations produced similar results. The rotated loadings are presented unless otherwise noted.

\section{Results}

During the follow-up period, 721 orofacial symptom episodes were reported, 478 (66\%) of which resulted in RDC examinations. These examinations classified 235 participants as TMD onset cases. In addition, 338 participants who did not report orofacial symptom episodes were selected at random for examination, and 25 of these examinations (7\%) were classified with TMD onset. Thus, a total of 260 examiner-verified cases of TMD onset were ascertained (see Bair et al. ${ }^{5}$ for further detail).

\section{Univariate Findings}

Measures of Global Psychological and Somatic Function, Stress and Mood (see Table 1)-Among the psychological characteristics reported in Table 1, the highest hazard ratio (HR) for predicting TMD onset emerged for the PILL (imputed HR=1.55), a measure of somatic symptoms. The effect was statistically significant, as demonstrated by the associated $95 \%$ confidence interval (1.33 to 1.66) that excluded the null of one. Also, greater scores on all SCL90R subscales were associated with increased incidence of TMD, with hazard ratios ranging from 1.22 (for the Phobia and Paranoid scales) to 1.44 for the Somatization scale. For both the PILL and SCL90R scales, the rate of TMD was highest for people in the upper tercile of the scales' distributions, whereas the lower- and mid-terciles differed to a smaller degree.

A greater degree of PTSD symptoms, as measured by the PTSD Checklist for Civilians, was associated with statistically-significantly greater TMD incidence (HR=1.38). Regarding personality as measured by the EPQ-R, neuroticism was associated with increased rates of TMD onset, with a hazard ratio of 1.28 , while extraversion was not associated with statistically significant variation in TMD incidence. Higher scores on the Perceived Stress Scale predicted increased incidence of TMD $(\mathrm{HR}=1.34)$, and a greater number $(\mathrm{HR}=1.30)$ and impact $(\mathrm{HR}=1.27)$ of negative events reported on the Life Experiences Survey predicted increased rates of TMD onset. Both trait and state anxiety were associated with increased incidence of TMD, with hazard ratios of 1.4 and 1.22, respectively. Negative affect 
$(\mathrm{HR}=1.24)$ and positive affect $(\mathrm{HR}=0.8)$, measured with the POMS-Bi, were associated with increased and decreased rates of TMD onset, respectively. Across most measures, hazard ratios and their $95 \%$ confidence intervals were only slightly lower when using imputed versus non-imputed data.

Measures of Active and Passive Coping and Reactivity (see Table 1)-None of the subscales of the Pain Catastrophizing Scale (Rumination, Magnification, Helplessness) predicted TMD onset to a statistically significant degree, although the Helplessness scale was weakly significant when using imputed data $(\mathrm{HR}=1.12)$. Likewise, no subscales from the Coping Strategies Questionnaire were statistically significant predictors of TMD incidence. The Kohn Reactivity Scale also was not a significant predictor of TMD onset.

\section{Principal Component Analysis (PCA)}

As in our original PCA ${ }^{30}$, a four-component solution emerged based on the scree plot and parallel analysis (See Supplementary e-Figure 1). The loadings for the PCA model are shown in Table 2 . The four components, which are consistent with our previous PCA, are labeled: 1) Global Psychological and Somatic Symptoms (high loadings from all SCL-90-R scales, the PILL, and the LSL/PCL-C PTSD symptom scale); 2) Stress and Negative Affectivity (high loadings from both State and Trait Anxiety, Perceived Stress, POMS Negative Affect, and EPQ-R Neuroticism; negative loadings for POMS Positive Affect and EPQ-R Extraversion); 3) Passive Pain Coping (positive loading from all three PCS subscales, the Praying and Hoping subscale of the CSQ-R, and the Kohn score); 4) Active Pain Coping (positive loadings from the remaining CSQ-R subscales). These four components were used in further univariate and multivariable analyses presented below.

Univariate Analyses of PCA Components as Predictors of First-Onset TMDIn univariate analyses of single PCA scores, high levels of Global Psychological and Somatic Symptoms (imputed HR=1.37) and Stress and Negative Affectivity (imputed $\mathrm{HR}=1.31$ ) predicted increased TMD incidence in both the unimputed and imputed analyses while Passive Pain Coping was a weaker, though statistically significant, predictor of TMD incidence (imputed HR=1.16, see Supplementary e-Table 1 for detailed information).

Table 3 presents the outcomes of analyses examining PCA components as predictors of TMD onset, stratified separately by age, gender, and race/ethnicity. In general, PCA components did not interact with demographic factors in predicting TMD onset, such that hazard ratios were similar across age groups, gender and race/ethnicity. However, Global Psychological and Somatic Symptoms was the exception, showing a modest interaction with age group ( $\mathrm{p}=0.03$ ), such that this component was a stronger predictor of TMD incidence in the two younger age groups compared to the 35-44 year old group.

\section{Multivariable Analyses of PCA Components as Predictors of First-Onset TMD}

-In fully-adjusted models (i.e., including study site and demographic factors) that examined main effects of multiple PCA components predicting TMD incidence after controlling for the other components, Global Psychological and Somatic Symptoms remained the only strong predictor (imputed $H R=1.33$, Table 4). The Stress and Negative Affectivity component was a weakly significant predictor in the unimputed analysis, but did not significantly predict TMD onset in the analysis using imputed data $(\mathrm{HR}=1.12)$.

The next multivariable analyses examined the two-way interactions among PCA components. The findings indicated that Global Psychological and Somatic Symptoms interacted with each of the other components in predicting TMD onset (all p's < 0.01). The pattern of findings was similar for all factors. Specifically, when Psychological and Somatic 
Symptom scores were low, the other components significantly predicted TMD onset. This pattern of results is depicted for Global Psychological and Somatic Symptoms and Stress and Negative Affectivity. After controlling for study site and demographic factors, the twoway interaction was statistically significant ( $\mathrm{p}=0.004$, see imputed model in Supplementary e-Table 2). As shown in Figure 1, the interaction indicated that Stress and Negative Affectivity significantly predicted TMD onset when Global Psychological and Somatic Symptoms were low (HR for Stress and Negative Affectivity $=1.30$ ), but not when Global Psychological and Somatic Symptoms were moderate or high (HR for Stress and Negative Affectivity $=0.96$ ).

Using the second multivariable approach of random forest models, the PILL emerged as the most important predictor of TMD incidence, based on its variable importance score (VIS) of 100. The second most important predictor, the Perceived Stress Scale, contributed much less to the predictive accuracy of the model (VIS=14.3), as did the SCL90R Anxiety (VIS=8.9) and Obsessive-Compulsive (VIS=7.5) scores, the CSQ Ignoring Pain score (VIS=5.2), the State Anxiety Inventory (VIS=5.0), the SCL90R Somatization Scale (VIS=4.8), and the LES Sum of Negative Events score (VIS=3.1).

Three partial dependence plots from the random forest model were selected to illustrate effects from different constructs showing relatively high variable importance scores (see Figure 2). These variables were chosen for presentation from among the variables with the highest variable importance scores to illustrate different non-linear patterns and to present examples of findings from multiple psychological domains. Different ranges for the y-axis scales were used to illustrate the full degree of variation in TMD incidence across variables that differed in importance. For PILL scores, the predicted TMD incidence remained at a constant low level below a score of approximately 95, at which time there was a linear increase in risk up to a score of approximately 140, at which time further increases in PILL scores did not confer additional risk. In contrast, for Perceived Stress Scores, a slight ushaped function emerged, such that risk of TMD onset was slightly higher at a score of zero than at a score of 15, above which, risk of TMD onset increased in linear fashion through the remainder of the scale range. For the CSQ Ignoring Pain Sensations scale, TMD incidence was greatest at a score of 0 and decreased in linear fashion until a score of approximately two, beyond which incidence increased slightly.

\section{Discussion}

These findings identify several psychological variables that represent premorbid risk factors for first onset of TMD. Based on univariate analyses, psychological variables that predicted TMD incidence include measures of somatic symptoms, general psychological symptoms, negative mood, and multiple measures of stress, including PTSD symptoms, perceived stress, and recalled life events. Measures of catastrophizing and active pain coping, wellestablished constructs associated with chronic pain, were not significant predictors of TMD first-onset. The largest hazard ratios emerged for measures of somatic symptoms. These findings are consistent with the recently reported outcomes from our OPPERA case-control study, in which measures of somatic symptoms were the psychological variables that differed most markedly between TMD cases and TMD-free controls ${ }^{30}$, while measures of negative mood and stress showed more modest, albeit significant, associations with chronic TMD in that study. The generally consistent findings of the prospective and case-control studies are notable, because the designs differ in at least two important dimensions. First, the case-control study recruited chronic TMD cases, while the first-onset TMD cases captured by the prospective study exhibit more acute symptoms by definition. The findings of generally similar psychological risk factors for chronic TMD and first-onset, typically acute TMD, suggest that these psychological factors are associated with both onset and chronicity 
of TMD. Second, the case-control study ascertained case status and psychological function concurrently, while in the prospective study psychological assessment was completed months or years before case classification. This implies that the influence of these psychological factors extends over a long time period.

The prospective nature of the OPPERA study identifies these psychological factors as predisposing risk factors for the development of TMD pain. Few previous studies investigating psychological factors related to TMD have employed a prospective design. Members of this research group reported that premorbid measures of depression, perceived stress, and mood state obtained at baseline were significant predictors of new onset TMD in a sample of healthy young females. ${ }^{81}$ Also, Aggarwal and colleagues ${ }^{2}$ showed that health anxiety predicted future development of chronic orofacial pain in adults, and depression, somatization and life satisfaction predicted TMD onset in adolescents. ${ }^{18,49}$ Additional studies implicate psychological variables as premorbid risk factors for development of for other chronic pain conditions, including chronic widespread pain ${ }^{58}$, regional musculoskeletal pain ${ }^{60}$, and low back pain. ${ }^{50,51,60}$

As in our previous report ${ }^{30}$, PCA revealed that our psychological instruments assessed four psychological domains, Global Psychological and Somatic Symptoms, Stress and Negative Affectivity, Passive Coping, and Active Coping. Not surprisingly, the Global Psychological and Somatic Symptoms component, on which measures of somatic symptoms loaded, was the strongest predictor of TMD onset. In univariate analyses, Stress and Negative Affectivity also predicted incident TMD; however, this association became weak or non-significant in multivariable analyses that adjusted for the other principal components. Interestingly, in individuals with moderate to high Global Psychological and Somatic Symptoms, Stress and Negative Affectivity did not significantly predict TMD onset; however, when Global Psychological and Somatic Symptoms were low, Stress and Negative Affectivity significantly predicted TMD incidence. This suggests that Stress and Negative Affectivity does not additively contribute to TMD risk over and above Global Psychological and Somatic Symptoms, rather in the absence of global symptomatology, stress/negative affect emerges as a potentially important risk factor. This interaction was modest in magnitude and should be interpreted cautiously; however, based on these results, future studies designed to examine psychological risk factors for TMD may benefit from assessing both of these domains.

Passive Pain Coping failed to predict first-onset TMD in our prospective study, which contrasts with previous case-control findings reported from the OPPERA Study ${ }^{30}$; additionally, other studies indicated higher levels of pain catastrophizing, a component of passive pain coping, among people with TMD. ${ }^{10,70}$ However, that passive pain coping failed to predict first-onset of TMD pain is not particularly surprising given the method of assessment of this construct. In assessing catastrophizing, for example, individuals with pain are asked to report how they respond to their existing pain condition. However, TMD-free individuals, such as the participants at enrollment in our prospective cohort, were asked to indicate how they respond to pain in general when it does occur, which represents a more hypothetical construct. Indeed, in pain-free adults, such measures of general catastrophizing have not consistently predicted responses to experimental pain, while post hoc assessments of individuals' catastrophic cognitions when they were experiencing experimental pain have been associated with laboratory pain responses ${ }^{10,22}$. Thus, measures of catastrophizing, and perhaps other forms of pain coping, may be associated with pain in a context-dependent manner. In addition, catastrophizing may increase risk for transition from acute to chronic pain rather than predicting pain onset. 
Analyses stratified by demographic factors revealed that psychological risk factors for firstonset TMD were generally similar across age, sex, and racial and ethnic groups. One exception was that Global Psychological and Somatic Symptoms predicted TMD incidence more strongly in the two younger age groups $(18-24,25-34$ years) versus the older age group (35-44 years). Interestingly, this older group had the highest incidence of first-onset TMD (see ${ }^{79}$ ), and the present findings suggest that either unmeasured psychological variables or non-psychological factors confer this increased risk of TMD onset in this age group. However, it should be noted that the interaction of age with Global Psychological and Somatic Symptoms in predicting TMD onset, though statistically significant, was modest in magnitude and needs to be replicated.

In addition to more traditional regression-based multivariable analyses using the PCA factor scores, random forest models provided an additional, more exploratory multivariable approach that was able to accommodate the individual variables. The random forest models identified similar predictors of TMD onset as observed in the univariate analyses, with the PILL being the strongest predictor of TMD onset. Other variables with non-zero variable importance scores, suggesting at least modest predictive ability even after accounting for somatic symptoms, included the Perceived Stress Scale, State Anxiety, the SCL90R anxiety, somatization, and obsessive-compulsive scales, and the CSQ Ignoring Pain Sensations Scale. This latter scale did not emerge as a predictor in the univariate model, suggesting that this coping strategy may provide some predictive value after adjusting for the effects of other psychological variables. The depicted partial dependence plots indicate that the association of a given predictor with TMD onset can be non-linear, and the pattern varies across variables. For the three plotted variables, the non-linear patterns generally were consistent with incidence rates reported for terciles of those variables in the univariate analysis. Given that the multivariable regression used factor scores and the random forest used individual measures, direct comparisons are not possible. However, in univariate analyses as well as both multivariable approaches the somatic symptom construct represented the strongest predictor of TMD onset, suggesting convergence of findings regarding somatic symptoms across analytic methods.

While multiple psychological measures predicted TMD onset in univariate analyses, results of multivariable models provide strong evidence that reported somatic symptoms represents the strongest predictor of incident TMD in this analysis. Increased somatic symptom reporting could result from altered physiological function leading to increased symptoms and/or from altered central nervous system function resulting in greater awareness of somatic and interoceptive cues. The mechanisms whereby somatic symptoms increase risk for TMD remain unknown. Perhaps somatic symptoms may reflect or be associated with health behaviors or conditions that increase risk of TMD. For example, somatic symptoms could result from parafunctional behaviors (e.g. bruxism, nail-biting), or other behavioral changes (e.g. sleep disturbance), which could in turn increase risk for TMD. ${ }^{62}$ Alternatively, somatic symptoms may reflect underlying physiological perturbations, and these physiological perturbations might contribute directly to the pathogenesis of TMD. Indeed, enhanced responses in immune and inflammatory systems have been associated with somatic symptoms ${ }^{4,26,55}$, and these biological pathways have also been implicated in TMD in cross-sectional studies. ${ }^{80}$ Similarly, brain imaging findings suggest that overlapping neural alterations may contribute to somatization and chronic pain states. ${ }^{32,83}$ Hence, it seems plausible that in our cohort, high somatic symptom reporting at baseline could reflect alterations in biological pathways that may increase risk for TMD onset. In any event, increased reporting of somatic symptoms represents a strong risk factor for development of TMD, and additional investigation of this construct is warranted. 
The findings of this study should be interpreted in light of its limitations. First, some variables identified as significant risk factors in univariate analyses would not remain significant in a related multivariable analysis (e.g., the PILL score and the SCL90R Somatization score likely share predictive variance). This is supported by findings that both measures load onto a single principal component and by results from random forest models showing that the variable importance ranking of the SCL90R Somatization score was considerably lower in the random forest model than in the univariate analysis. Second, while we examined some of the potential interactions among factors (e.g. demographic measures and PCA components), many other possible interactions were not tested (e.g. between individual psychological measures) due to the exceedingly large number of statistical tests this would require, and we chose to remain conservative in our explorations. Third, the analyses herein do not examine potentially important associations between psychological variables and other phenotypic measures, such as those presented in other manuscripts in this volume. Instead, cross-domain analyses are presented elsewhere in this volume. ${ }^{6}$

These limitations notwithstanding, the current findings verify etiologic influences of several psychological variables that have been implicated as possible risk factors for TMD in previous cross-sectional studies. The strongest predictors of TMD incidence were measures of somatic symptoms and their associated latent construct of Global Psychological and Somatic Symptoms, derived from PCA. In general, these psychological influences were similar across demographic categories. Future analyses will examine associations of these psychological variables with transition from acute to chronic pain, and changes in psychological functioning that accompany onset of TMD will also be explored.

\section{Supplementary Material}

Refer to Web version on PubMed Central for supplementary material.

\section{Acknowledgments}

The authors would like to thank the OPPERA research staff at each of four study sites and the data management center for their invaluable contributions to this work. In addition, we express our gratitude to the participants who have devoted time and effort in support of this research.

This work was supported by NIH grant U01DE017018. The OPPERA program also acknowledges resources specifically provided for this project by the respective host universities: University at Buffalo, University of Florida, University of Maryland-Baltimore, and University of North Carolina-Chapel Hill. Roger Fillingim and Gary Slade are consultants and equity stock holders, and William Maixner and Luda Diatchenko are cofounders and equity stock holders in Algynomics, Inc., a company providing research services in personalized pain medication and diagnostics.

\section{References}

1. Adams J. A computer experiment to evaluate regression strategies. Proceedings of the American Statistical Association Section on Statistical Computing. 1991

2. Aggarwal VR, Macfarlane GJ, Farragher TM, McBeth J. Risk factors for onset of chronic oro-facial pain--results of the North Cheshire oro-facial pain prospective population study. Pain. 2010; 149:354-359. [PubMed: 20304556]

3. Almansa C, Rey E, Sanchez RG, Sanchez AA, Diaz-Rubio M. Prevalence of functional gastrointestinal disorders in patients with fibromyalgia and the role of psychologic distress. Clin Gastroenterol Hepatol. 2009; 7:438-445. [PubMed: 19138763]

4. Anderson G, Maes M, Berk M. Biological underpinnings of the commonalities in depression, somatization, and Chronic Fatigue Syndrome. Med Hypotheses. 2012; 78:752-756. [PubMed: 22445460] 
5. Bair E, Brownstein NC, Ohrbach R, Greenspan JD, Dubner R, Fillingim RB, Diatchenko L, Smith S, Maixner W, Gonzalez Y, Gordon S, Lim PF, Ribeiro-Dasilva M, Dampier D, Knott C, Slade GD. Study design, methods, sample characteristics and loss-to-follow-up: the OPPERA prospective cohort study. J Pain, Submitted. 2013

6. Bair E, By K, Mulkey F, Baraian C, Rothwell R, Reynolds M, Miller V, Gonzalez Y, Gordon S, Ribeiro-Dasilva M, Lim PF, Greenspan JD, Dubner R, Fillingim RB, Diatchenko L, Dampier D, Knott C, Ohrbach R, Maixner W, Slade GD. Multivariable modeling of phenotypic risk factors across four domains: genes, pain amplification, psychological distress and environmental contribution. J Pain, Submitted. 2012

7. Boyce PM, Koloski NA, Talley NJ. Irritable bowel syndrome according to varying diagnostic criteria: are the new Rome II criteria unnecessarily restrictive for research and practice? Am J Gastroenterol. 2000; 95:3176-3183. [PubMed: 11095338]

8. Breiman LL. Random forests. Machine Learning. 2001; 45:5-32.

9. Burris JL, Cyders MA, De LR, Smith GT, Carlson CR. Posttraumatic stress disorder symptoms and chronic orofacial pain: an empirical examination of the mutual maintenance model. J Orofac Pain. 2009; 23:243-252. [PubMed: 19639104]

10. Campbell CM, Kronfli T, Buenaver LF, Smith MT, Berna C, Haythornthwaite JA, Edwards RR. Situational versus dispositional measurement of catastrophizing: associations with pain responses in multiple samples. J Pain. 2010; 11:443-453. [PubMed: 20439057]

11. Carlson CR, Okeson JP, Falace DA, Nitz AJ, Curran SL, Anderson D. Comparison of psychologic and physiologic functioning between patients with masticatory muscle pain and matched controls. J Orofacial Pain. 1993; 7:15-22. [PubMed: 8467294]

12. Cohen S, Kamarck T, Mermelstein R. A global measure of perceived stress. J Health Soc Behav. 1983; 24:385-396. [PubMed: 6668417]

13. Cook AJ, Chastain DC. The classification of patients with chronic pain: age and sex differences. Pain Res Manag. 2001; 6:142-151. [PubMed: 11854777]

14. de DP, Del BE, Gori-Savellini S, Manzoni GC, Martucci N, Nappi G, Savoldi F. Personality patterns of headache sufferers. Cephalalgia. 1983; (3 Suppl 1):195-214. 195-214. [PubMed: 6616603]

15. Derogatis, L. The SCL-90-R: administration, scoring and procedures manual. Minneapolis, MN: National Computer Systems, Inc; 1994.

16. Diatchenko L, Nackley AG, Slade GD, Fillingim RB, Maixner W. Idiopathic pain disorders-pathways of vulnerability. Pain. 2006; 123:226-230. [PubMed: 16777329]

17. Dubreuil DL, Kohn PM. Reactivity and response to pain. Pers Indiv Diff. 1986; 7:907-909.

18. Dunn KM, Jordan KP, Mancl L, Drangsholt MT, LeResche L. Trajectories of pain in adolescents: a prospective cohort study. Pain. 2011; 152:66-73. [PubMed: 20971561]

19. Dworkin, RH.; Breitbart, WS. Psychosocial aspects of pain: a handbook for health care providers. Seattle: IASP Press; 2004.

20. Dworkin SF, Huggins KH, LeResche L, Von Korff M, Howard J, Truelove E, Sommers E. Epidemiology of signs and symptoms in temporomandibular disorders: clinical signs in cases and controls. J Am Dent Assoc. 1990; 120:273-281. [PubMed: 2312947]

21. Dworkin SF, LeResche L. Research diagnostic criteria for temporomandibular disorders. J Craniomandib Disord. 1992; 6:302-355.

22. Edwards RR, Campbell CM, Fillingim RB. Catastrophizing and experimental pain sensitivity: only in vivo reports of catastrophic cognitions correlate with pain responses. J Pain. 2005; 6:338-339. [PubMed: 15890636]

23. Eli I. Psychosocial factors in the etiology, diagnosis and management of temporomandibular disorders. Alpha Omegan. 2003; 96:20-23. [PubMed: 12955778]

24. Elliott R, Fox CM, Beltyukova SA, Stone GE, Gunderson J, Zhang X. Deconstructing therapy outcome measurement with Rasch analysis of a measure of general clinical distress: the Symptom Checklist-90-Revised. Psychol Assess. 2006; 18:359-372. [PubMed: 17154757]

25. Epker J, Gatchel RJ. Coping profile differences in the biopsychosocial functioning of patients with temporomandibular disorder. Psychosom Med. 2000; 62:69-75. [PubMed: 10705913] 
26. Euteneuer F, Schwarz MJ, Hennings A, Riemer S, Stapf T, Selberdinger V, Rief W. Psychobiological aspects of somatization syndromes: contributions of inflammatory cytokines and neopterin. Psychiatry Res. 2012; 195:60-65. [PubMed: 21864915]

27. Eysenck, HJ.; Eysenck, SBG. Manual of the ysenck Personality Questionnaire. San Diego, CA: Educational and Industrial Testing Service; 1994.

28. Eysenck SBG, Eysenck HJ, Barrett P. A revised version of the psychoticism scale. Personality and Indivdual Differences. 1985; 6:21-29.

29. Ferrando M, Andreu Y, Galdon MJ, Dura E, Poveda R, Bagan JV. Psychological variables and temporomandibular disorders: distress, coping, and personality. Oral Surg Oral Med Oral Pathol Oral Radiol Endod. 2004; 98:153-160. [PubMed: 15316541]

30. Fillingim RB, Ohrbach R, Greenspan JD, Knott C, Dubner R, Bair E, Baraian C, Slade GD, Maixner W. Potential psychosocial risk factors for chronic TMD: descriptive data and empirically identified domains from the OPPERA case-control study. J Pain. 2011; 12:T46-T60. [PubMed: 22074752]

31. Fishbain DA, Lewis JE, Gao J, Cole B, Steele RR. Is chronic pain associated with somatization/ hypochondriasis? An evidence-based structured review. Pain Pract. 2009; 9:449-467. [PubMed: 19735366]

32. Garcia-Campayo J, Fayed N, Serrano-Blanco A, Roca M. Brain dysfunction behind functional symptoms: neuroimaging and somatoform, conversive, and dissociative disorders. Curr Opin Psychiatry. 2009; 22:224-231. [PubMed: 19553880]

33. Garofalo JP, Gatchel RJ, Wesley AL, Ellis E. Predicting chronicity in acute temporomandibular joint disorders using the research diagnostic criteria. Journal of the American Dental Association. 1998; 129:438-447. [PubMed: 9573694]

34. Gatchel RJ, Peng YB, Peters ML, Fuchs PN, Turk DC. The biopsychosocial approach to chronic pain: scientific advances and future directions. Psychol Bull. 2007; 133:581-624. [PubMed: 17592957]

35. Greenland S. Invited commentary: variable selection versus shrinkage in the control of multiple confounders. Am J Epidemiol. 2008; 167:523-529. [PubMed: 18227100]

36. Hastie BA, Riley JL III, Fillingim RB. Ethnic differences in pain coping: factor structure of the coping strategies questionnaire and coping strategies questionnaire-revised. J Pain. 2004; 5:304 316. [PubMed: 15336635]

37. Hastie, T.; Tibshirani, R.; Friedman, J. The elements of statistical learning: data mining, inference, and prediction. New York: Springer; 2009.

38. Hazlett-Stevens H, Craske MG, Mayer EA, Chang L, Naliboff BD. Prevalence of irritable bowel syndrome among university students. The roles of worry, neuroticism, anxiety sensitivity and visceral anxiety. J Psychosom Res. 2003; 55:501-505. [PubMed: 14642979]

39. Hu YJ, Ku TH, Jan RH, Wang K, Tseng YC, Yang SF. Decision tree-based learning to predict patient controlled analgesia consumption and readjustment. BMC Med Inform Decis Mak. 2012; 12:131. [PubMed: 23148492]

40. Ishwaran H, Kogalur UB, Blackstone EH, Lauer MS. Random survival forests. Annals of Applied Statistics 2. 2008:841-860.

41. Isong U, Gansky SA, Plesh O. Temporomandibular joint and muscle disorder-type pain in U.S. adults: the National Health Interview Survey. J Orofac Pain. 2008; 22:317-322. [PubMed: 19090404]

42. Keefe FJ, Rumble ME, Scipio CD, Giordano LA, Perri LM. Psychological aspects of persistent pain: current state of the science. J Pain. 2004; 5:195-211. [PubMed: 15162342]

43. Kim HI, Lee JY, Kim YK, Kho HS. Clinical and psychological characteristics of TMD patients with trauma history. Oral Dis. 2010; 16:188-192. [PubMed: 19758407]

44. Kindler S, Samietz S, Houshmand M, Grabe HJ, Bernhardt O, Biffar R, Kocher T, Meyer G, Volzke H, Metelmann HR, Schwahn C. Depressive and anxiety symptoms as risk factors for temporomandibular joint pain: a prospective cohort study in the general population. J Pain. 2012; 13:1188-1197. [PubMed: 23141187]

45. Kino K, Sugisaki M, Haketa T, Amemori Y, Ishikawa T, Shibuya T, Sato F, Amagasa T, Shibuya T, Tanabe H, Yoda T, Sakamoto I, Omura K, Miyaoka H. The comparison between pains, 
difficulties in function, and associating factors of patients in subtypes of temporomandibular disorders. J Oral Rehabil. 2005; 32:315-325. [PubMed: 15842238]

46. Kino K, Sugisaki M, Ishikawa T, Shibuya T, Amagasa T, Miyaoka H. Preliminary psychologic survey of orofacial outpatients. Part 1: Predictors of anxiety or depression. J Orofac Pain. 2001; 15:235-244. [PubMed: 11575194]

47. Kohn, PM. Sensation-seeking, augmenting-reducing, and strength of the nervous system. In: Spence, JT.; Izard, DE., editors. Motivation, Emotion, and Personality. Amsterdam: Elsevier; 1985. p. 167-173.

48. Krogstad BS, Jokstad A, Dahl BL, Soboleva U. Somatic complaints, psychologic distress, and treatment outcome in two groups of TMD patients, one previously subjected to whiplash injury. $\mathbf{J}$ Orofac Pain. 1998; 12:136-144. [PubMed: 9656891]

49. LeResche L, Mancl LA, Drangsholt MT, Huang G, Von KM. Predictors of onset of facial pain and temporomandibular disorders in early adolescence. Pain. 2007; 129:269-278. [PubMed: 17134830]

50. Linton SJ. A review of psychological risk factors in back and neck pain. Spine. 2000; 25:11481156. [PubMed: 10788861]

51. Linton SJ. Do psychological factors increase the risk for back pain in the general population in both a cross-sectional and prospective analysis? Eur J Pain. 2005; 9:355-361. [PubMed: 15979015]

52. Loader, C. Local regression and likelihood. New York: Springer; 1999.

53. Lorr, M.; McNair, DM. Profile of Mood States: Bipolar Form. San Diego: Educational and Industrial Testing Service; 1988.

54. Macfarlane TV, Gray RJM, Kincey J, Worthington HV. Factors associated with the temporomandibular disorder, pain dysfunction syndrome (PDS): Manchester case-control study. Oral Dis. 2001; 7:321-330. [PubMed: 11834094]

55. Maes M. Inflammatory and oxidative and nitrosative stress pathways underpinning chronic fatigue, somatization and psychosomatic symptoms. Curr Opin Psychiatry. 2009; 22:75-83. [PubMed: 19127706]

56. Maixner W, Diatchenko L, Dubner R, Fillingim RB, Greenspan JD, Knott C, Ohrbach R, Weir B, Slade GD. Orofacial Pain Prospective Evaluation and Risk Assessment study--the OPPERA study. J Pain. 2011; 12:T4-T11. [PubMed: 22074751]

57. Manfredini D, Winocur E, Ahlberg J, Guarda-Nardini L, Lobbezoo F. Psychosocial impairment in temporomandibular disorders patients. RDC/TMD axis II findings from a multicentre study. $\mathrm{J}$ Dent. 2010; 38:765-772. [PubMed: 20600559]

58. McBeth J, Macfarlane GJ, Benjamin S, Silman AJ. Features of somatization predict the onset of chronic widespread pain: results of a large population-based study. Arthritis Rheum. 2001; 44:940-946. [PubMed: 11315933]

59. McDermid AJ, Rollman GB, McCain GA. Generalized hypervigilance in fibromyalgia: evidence of perceptual amplification. Pain. 1996; 66:133-144. [PubMed: 8880834]

60. Nahit ES, Pritchard CM, Cherry NM, Silman AJ, Macfarlane GJ. The influence of work related psychosocial factors and psychological distress on regional musculoskeletal pain: a study of newly employed workers. J Rheumatol. 2001; 28:1378-1384. [PubMed: 11409134]

61. Ohrbach R, Dworkin SF. Five-year outcomes in TMD: relationship of changes in pain to changes in physical and psychological variables. Pain. 1998; 74:315-326. [PubMed: 9520246]

62. Ohrbach R, Fillingim RB, Mulkey F, Gonzalez Y, Gordon S, Lim PF, Ribeiro-Dasilva M, Greenspan JD, Knott C, Maixner W, Slade G. Clinical orofacial characteristics associated with development of TMD: the OPPERA prospective cohort study. J Pain, Submitted. 2012

63. Ohrbach R, Sherman J, Beneduce C, Zittel-Palamara K, Pak Y. Extraction of RDC/TMD subscales from the symptom check list-90: does context alter respondent behavior? J Orofac Pain. 2008; 22:331-339. [PubMed: 19090406]

64. Osman A, Barrios FX, Gutierrez PM, Kopper BA, Merrifield T, Grittmann L. The Pain Catastrophizing Scale: further psychometric evaluation with adult samples. J Behav Med. 2000; 23:351-365. [PubMed: 10984864] 
65. Paap MC, Meijer RR, Van BJ, Pedersen G, Karterud S, Hellem FM, Haraldsen IR. A study of the dimensionality and measurement precision of the SCL-90-R using item response theory. Int $\mathrm{J}$ Methods Psychiatr Res. 2011; 20:e39-e55. [PubMed: 21812065]

66. Pallegama RW, Ranasinghe AW, Weerasinghe VS, Sitheeque MA. Anxiety and personality traits in patients with muscle related temporomandibular disorders. J Oral Rehabil. 2005; 32:701-707. [PubMed: 16159346]

67. Paul B, Leitner C, Vacariu G, Wick F, Zehetmayer S, Matzner M, Mittermaier C, Vanecek E, Ebenbichler G. Low-back pain assessment based on the Brief ICF Core Sets: diagnostic relevance of motor performance and psychological tests. Am J Phys Med Rehabil. 2008; 87:452-460. [PubMed: 18496247]

68. Pennebaker, JW. The psychology of physical symptoms. New York: Springer-Verlag; 1982.

69. Persson LO, Larsson BM, Nived K, Eberhardt K. The development of emotional distress in 158 patients with recently diagnosed rheumatoid arthritis: a prospective 5-year follow-up study. Scand J Rheumatol. 2005; 34:191-197. [PubMed: 16134724]

70. Quartana PJ, Buenaver LF, Edwards RR, Klick B, Haythornthwaite JA, Smith MT. Pain catastrophizing and salivary cortisol responses to laboratory pain testing in temporomandibular disorder and healthy participants. J Pain. 2010; 11:186-194. [PubMed: 19853521]

71. Riddle DL, Kong X, Jiranek WA. Two-year incidence and predictors of future knee arthroplasty in persons with symptomatic knee osteoarthritis: preliminary analysis of longitudinal data from the osteoarthritis initiative. Knee. 2009; 16:494-500. [PubMed: 19419874]

72. Riley JL III, Robinson ME. CSQ: five factors or fiction? Clin J Pain. 1997; 13:156-162. [PubMed: 9186023]

73. Rollman GB, Gillespie JM. The role of psychosocial factors in temporomandibular disorders. Current Review of Pain. 2000; 4:71-81. [PubMed: 10998718]

74. Rosenstiel AK, Keefe FJ. The use of coping strategies in chronic low back pain patients: Relationship to patient characteristics and current adjustment. Pain. 1983; 17:33-44. [PubMed: 6226916]

75. Sarason IG, Johnson JH, Siegel JM. Assessing the impact of life changes: development of the Life Experiences Survey. J Consult Clin Psychol. 1978; 46:932-946. [PubMed: 701572]

76. Schiphorst Preuper HR, Reneman MF, Boonstra AM, Dijkstra PU, Versteegen GJ, Geertzen JH. The relationship between psychosocial distress and disability assessed by the Symptom Checklist-90-Revised and Roland Morris Disability Questionnaire in patients with chronic low back pain. Spine J. 2007; 7:525-530. [PubMed: 17905314]

77. Shutty MS Jr, DeGood DE, Schwartz DP. Psychological dimensions of distress in chronic pain patients: a factor analytic study of symptom checklist-90 responses. J Consult Clin Psychol. 1986; 54:836-842. [PubMed: 3794030]

78. Slade GD, Bair E, By K, Mulkey F, Baraian C, Rothwell R, Reynolds M, Miller V, Gonzalez Y, Gordon S, Ribeiro-Dasilva M, Lim PF, Greenspan JD, Dubner R, Fillingim RB, Diatchenko L, Maixner W, Dampier D, Knott C, Ohrbach R. Study methods, recruitment, sociodemographic findings, and demographic representativeness in the OPPERA study. J Pain. 2011; 12:T12-T26. [PubMed: 22074749]

79. Slade GD, Bair E, By K, Mulkey F, Baraian C, Rothwell R, Reynolds M, Miller V, Gonzalez Y, Gordon S, Ribeiro-Dasilva M, Lim PF, Greenspan JD, Dubner R, Fillingim RB, Diatchenko L, Maixner W, Dampier D, Knott C, Ohrbach R. Socio-demographic characteristics associated with the development of TMD: the OPPERA prospective cohort study. J Pain, Submitted. 2012

80. Slade GD, Conrad MS, Diatchenko L, Rashid NU, Zhong S, Smith S, Rhodes J, Medvedev A, Makarov S, Maixner W, Nackley AG. Cytokine biomarkers and chronic pain: association of genes, transcription, and circulating proteins with temporomandibular disorders and widespread palpation tenderness. Pain. 2011; 152:2802-2812. [PubMed: 22000099]

81. Slade GD, Diatchenko L, Bhalang K, Sigurdsson A, Fillingim RB, Belfer I, Max MB, Goldman D, Maixner W. Influence of psychological factors on risk of temporomandibular disorders. J Dent Res. 2007; 86:1120-1125. [PubMed: 17959908]

82. Spielberger, CD.; Gorusch, RL.; Lushene, R.; Vagg, PR.; Jacobs, GA. Manual for the State-Trait Anxiety Inventory (Form Y1). Palo Alto, CA: Consulting Psychologists Press; 1983. 
83. Stein DJ, Muller J. Cognitive-affective neuroscience of somatization disorder and functional somatic syndromes: reconceptualizing the triad of depression-anxiety-somatic symptoms. CNS Spectr. 2008; 13:379-384. [PubMed: 18496475]

84. Sullivan MJ, Bishop S, Pivik J. The Pain Catastrophizing Scale: development and validation. Psychological Assessment. 1995; 7:524-532.

85. Talley NJ, Boyce PM, Jones M. Predictors of health care seeking for irritable bowel syndrome: a population based study [see comments]. Gut. 1997; 41:394-398. [PubMed: 9378398]

86. Thompson B, Daniel LG. Factor analytic evidence for the construct validity of scores: a historical overview and some guidelines. Educational and Psychological Measurement. 1996; 56:197-208.

87. Velly AM, Gornitsky M, Philippe P. Contributing factors to chronic myofascial pain: a casecontrol study. Pain. 2003; 104:491-499. [PubMed: 12927621]

88. Weathers, FW.; Litz, BT.; Herman, DS.; Huska, JA.; Keane, TM. The PTSD Checklist (PCL): Reliability, validity, and diagnostic utility; San Antonio, TX. Paper presented at the Meeting of the International Society for Traumatic Studies; 1993.

89. Wolfe F, Clauw DJ, Fitzcharles MA, Goldenberg DL, Katz RS, Mease P, Russell AS, Russell IJ, Winfield JB, Yunus MB. The American College of Rheumatology preliminary diagnostic criteria for fibromyalgia and measurement of symptom severity. Arthritis Care Res (Hoboken). 2010; 62:600-610. [PubMed: 20461783]

90. Yatani H, Studts J, Cordova M, Carlson CR, Okeson JP. Comparison of sleep quality and clinical and psychologic characteristics in patients with temporomandibular disorders. J Orofac Pain. 2002; 16:221-228. [PubMed: 12221738]

91. Zuckerman LA, Oliver JM, Hollingsworth HH, Austrin HR. A comparison of life events scoring methods as predictors of psychological symptomatology. J Human Stress. 12:64-70. 198. 


\section{Perspective}

This article reports that several premorbid psychological variables predict first-onset TMD in the OPPERA Study, a large prospective cohort study designed to discover causal determinants of TMD pain. Measures of somatic symptoms were most strongly associated with TMD onset, but perceived stress, previous life events, and negative affect also predicted TMD incidence. 


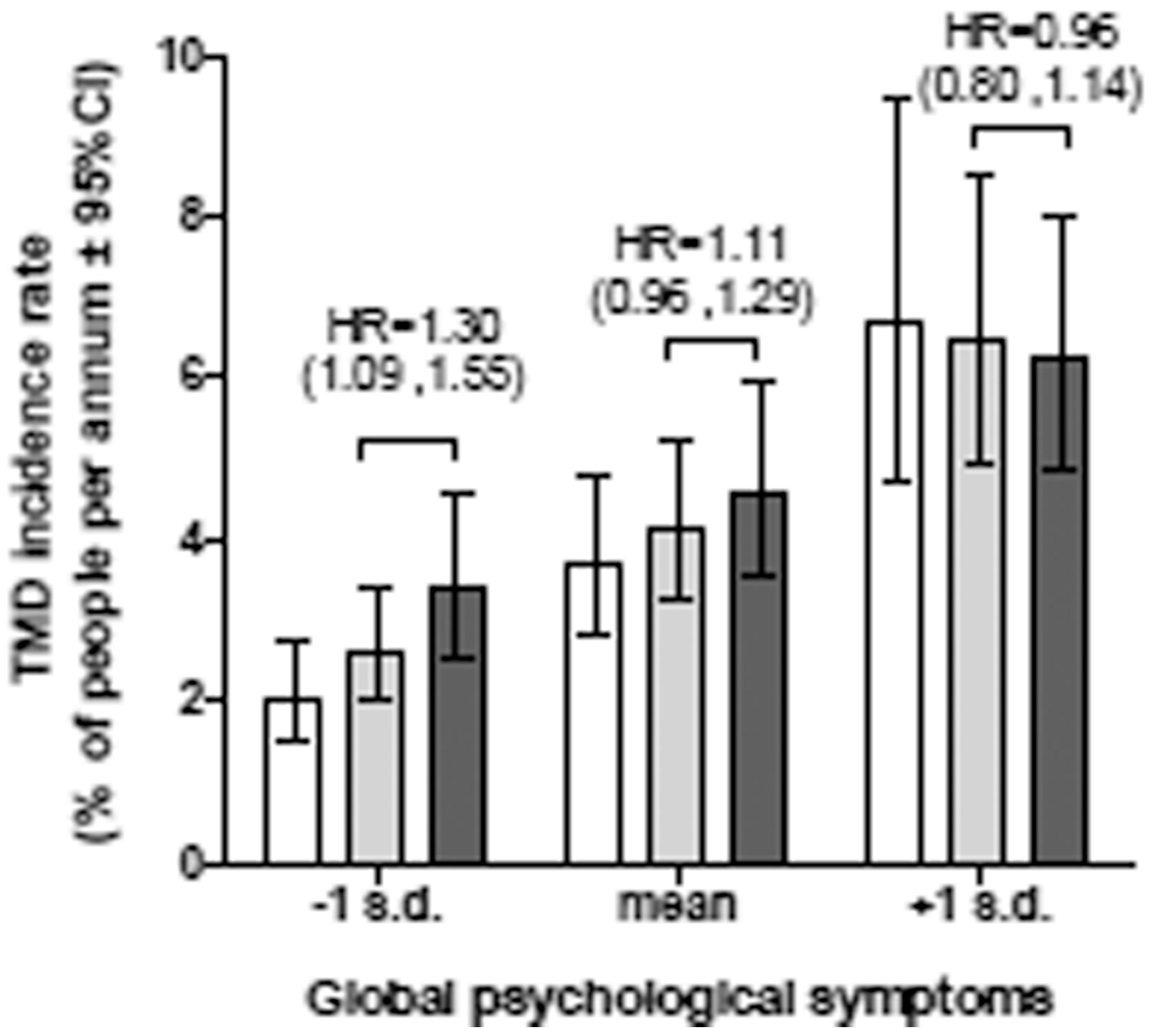

Figure 1.

Imputed TMD incidence rates and hazard ratios for stress and negative affectivity for three levels of Global Psychological and Somatic Symptoms. Each vertical bar depicts the TMD incidence rate for participants in the bottom (open bar), middle (light gray bar) and upper (dark gray bar) terciles of "Stress \& Negative Affectivity" scores at each tercile (from left to right) of "Global Psychological and Somatic Symptoms" scores. Incidence rates of firstonset TMD were computed using multivariable Poisson regression models with multiple imputation to account for subjects who were not examined as intended. Covariates were study site (categorical variable, 4 levels), age (in years, with rates estimated for three selected age groups: 20, 30 and 40 years), race/ethnicity (5 categories - rates not shown for 
"other/unknown" race category) and lifetime US residence (2 categories), Global Psychological and Somatic Symptoms principal component, Stress and Negative Affectivity principal component, and the interaction of the two principal components. For the interaction, $\mathrm{p}=.0004$. Hazard ratios (HR) represent the effect of 1 S.D. increase in the stress and negative affectivity on TMD incidence. They were calculated using multivariable Cox regression models with the same covariates described for the Poisson models. 

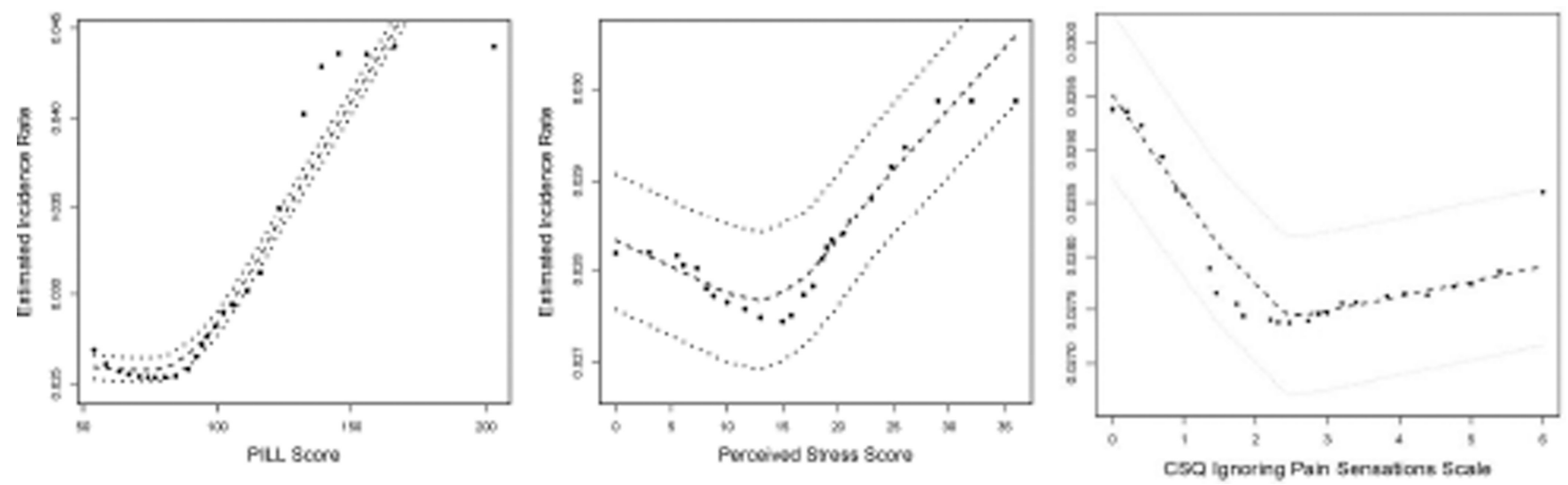

Figure 2.

Partial Dependence Plots for the Pennebaker Inventory of Limbic Languidness (PILL), the Perceived Stress Scale, and the Coping Strategies Questionnaire (CSQ) Ignoring Pain Sensations scale. The plots depict the estimated TMD incidence rate that would be observed at several values of the variable after averaging over the values of all other variables in the model. TMD incidence rates, expressed as cases per 100-person-years, were generated from random forest models that predicted TMD onset using study site, demographic variables, and psychosocial variables presented in Table 1 . Predicted values $(\bullet)$ are plotted together with LOESS-smoothed estimates (- - ) and their $95 \%$ confidence intervals ( $\cdots \cdots)$. Note that the $y$-axis scales vary across the three figures. 


\begin{tabular}{|c|c|c|c|c|c|c|c|c|c|}
\hline \multirow{3}{*}{ 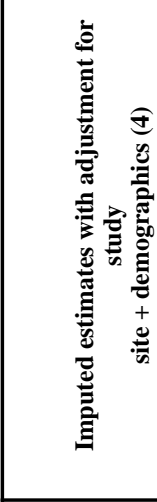 } & 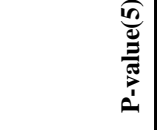 & $\begin{array}{l}\bar{\delta} \\
\dot{\vec{\sigma}} \\
\dot{\vec{v}}\end{array}$ & \begin{tabular}{|l}
$\overrightarrow{8}$ \\
$\dot{v}$
\end{tabular} & 客 & $\begin{array}{l}\vec{\delta} \\
\dot{v} \\
\dot{v}\end{array}$ & \begin{tabular}{|l}
$\overrightarrow{8}$ \\
$\dot{v}$ \\
$\dot{v}$
\end{tabular} & $\begin{array}{l}\bar{\delta} \\
\dot{\bar{\theta}} \\
\dot{v}\end{array}$ & $\begin{array}{l}\overrightarrow{0} \\
\dot{\vec{b}} \\
\dot{v}\end{array}$ & \begin{tabular}{|l}
$\overrightarrow{8}$ \\
$\dot{v}$ \\
$\dot{v}$
\end{tabular} \\
\hline & 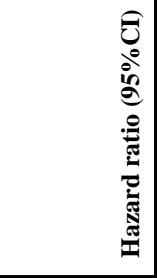 & 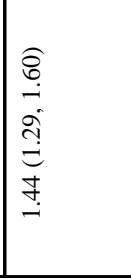 & 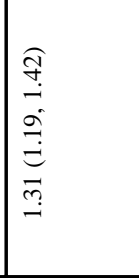 & 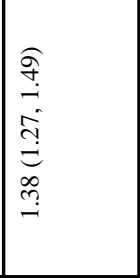 & 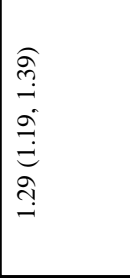 & 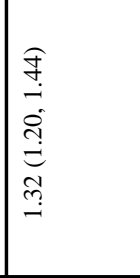 & 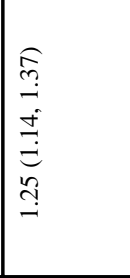 & 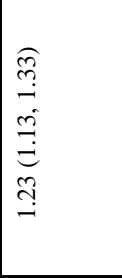 & 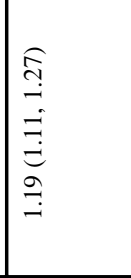 \\
\hline & $=$ & 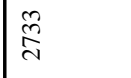 & त̂̀̃ & $\underset{\text { ते }}{\text { ते }}$ & సે & तิ & 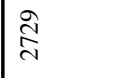 & స̂̀े & तิ \\
\hline \multirow{3}{*}{ 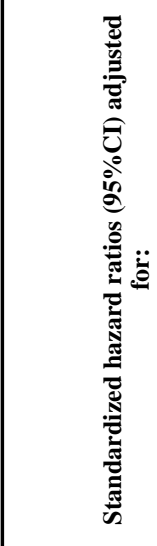 } & 号 & $\begin{array}{l}\bar{\delta} \\
\dot{\bar{\theta}}\end{array}$ & $\overrightarrow{\bar{o}}$ & $\begin{array}{l}\bar{\delta} \\
\dot{\bar{v}} \\
\end{array}$ & $\begin{array}{l}\bar{\delta} \\
\dot{\bar{\theta}}\end{array}$ & $\bar{\delta}$ & $\begin{array}{l}\bar{\delta} \\
\dot{\bar{\theta}}\end{array}$ & $\vec{b}$ & $\bar{\delta}$ \\
\hline & 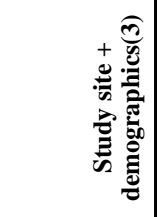 & 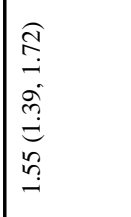 & 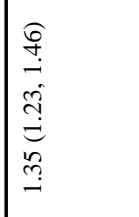 & 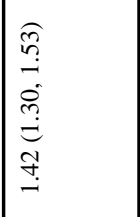 & 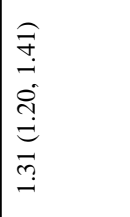 & 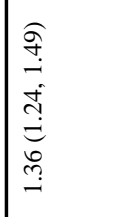 & 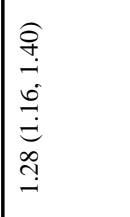 & 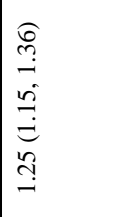 & 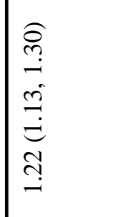 \\
\hline & 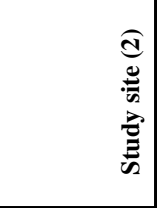 & 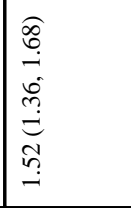 & 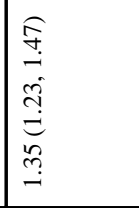 & 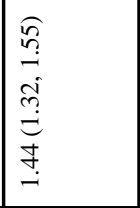 & 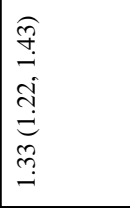 & 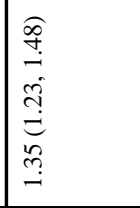 & 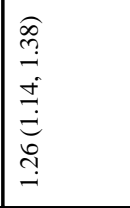 & 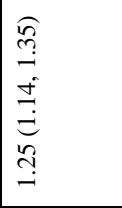 & 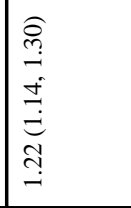 \\
\hline \multirow{3}{*}{ 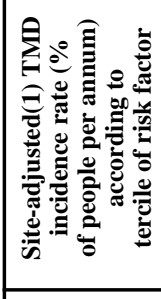 } & 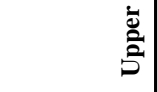 & 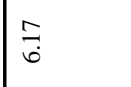 & 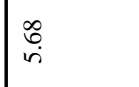 & $\begin{array}{l}\text { 离 } \\
\text { i. } \\
\text { in }\end{array}$ & & in & $\frac{m}{n}$ & & . \\
\hline & $\bar{z}$ & \begin{tabular}{|l}
0 \\
and \\
in \\
\end{tabular} & \begin{tabular}{|l}
$\hat{\infty}$ \\
i \\
\end{tabular} & $\begin{array}{l}\stackrel{8}{i} \\
\text { i }\end{array}$ & & 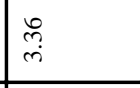 & $\stackrel{\circ}{\circ}$ & & 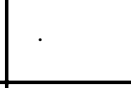 \\
\hline & 产 & i & $\begin{array}{l}\infty \\
\stackrel{a}{i} \\
\grave{i}\end{array}$ & 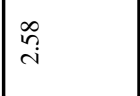 & & 常 & 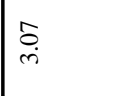 & & \\
\hline \multirow{2}{*}{ 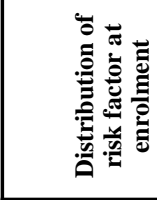 } & 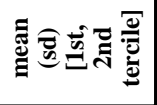 & 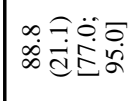 & 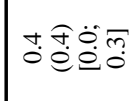 & 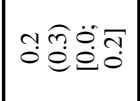 & 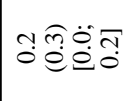 & 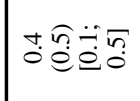 & 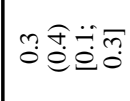 & ma & 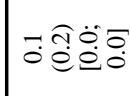 \\
\hline & $=$ & 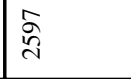 & 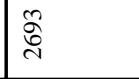 & 牶 & 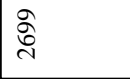 & 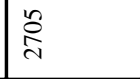 & $\underbrace{}_{\substack{0 \\
c}}$ & ते & స్ \\
\hline & 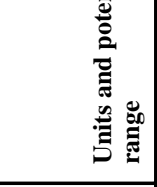 & 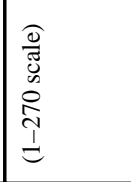 & 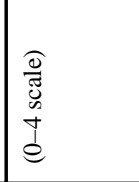 & 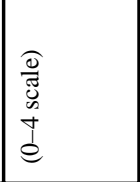 & 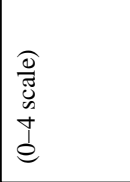 & 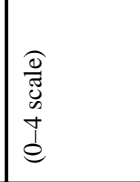 & 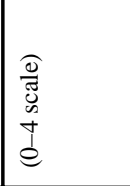 & 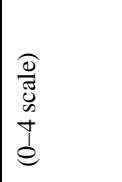 & 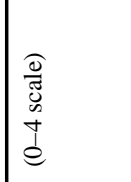 \\
\hline & 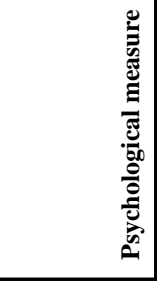 & 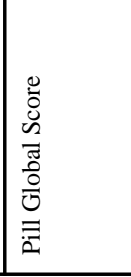 & 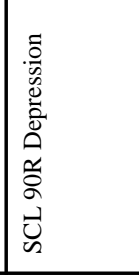 & 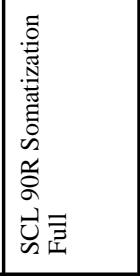 & 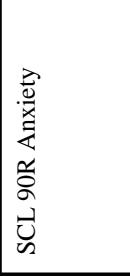 & 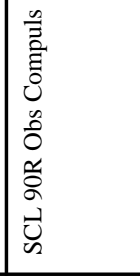 & 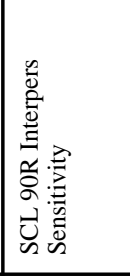 & 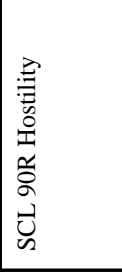 & 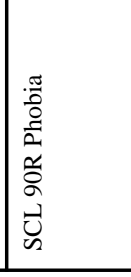 \\
\hline
\end{tabular}




\begin{tabular}{|c|c|c|c|c|c|c|c|c|c|c|}
\hline \multirow{3}{*}{ 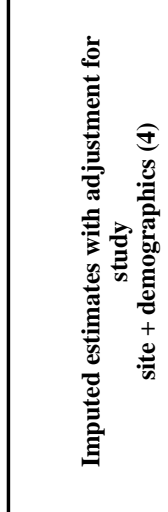 } & $\frac{\mathbb{n}}{\mathscr{E}}$ & $\begin{array}{l}\vec{\delta} \\
\dot{\dot{v}}\end{array}$ & $\vec{\delta}$ & \& & $\begin{array}{l}2 \\
2 \\
0 \\
0\end{array}$ & $\bar{\Xi}$ & $\begin{array}{l}\overline{8} \\
\dot{8} \\
\dot{\theta}\end{array}$ & & & $\begin{array}{l}\vec{\sigma} \\
\dot{0} \\
\dot{v}\end{array}$ \\
\hline & 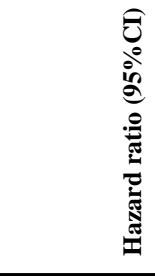 & 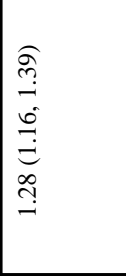 & 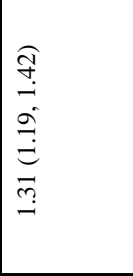 & 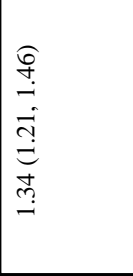 & 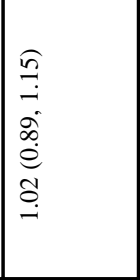 & 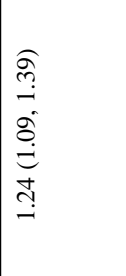 & 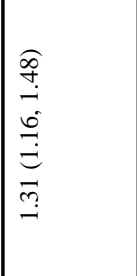 & & & 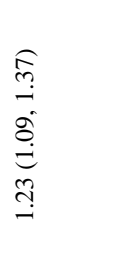 \\
\hline & $=$ & तิ & 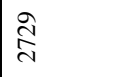 & : & 永 & 离 & 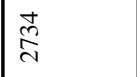 & & & 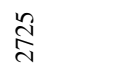 \\
\hline \multirow{3}{*}{ 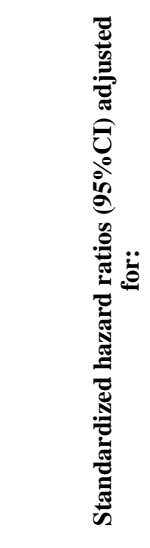 } & 总 & $\bar{\delta}$ & 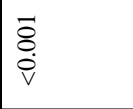 & छ & $\begin{array}{l}0 \\
0 \\
0 \\
0\end{array}$ & $\begin{array}{l}\bar{\delta} \\
\dot{0} \\
\dot{\nabla}\end{array}$ & $\begin{array}{l}\bar{\delta} \\
\dot{\theta} \\
\dot{\nabla}\end{array}$ & $\begin{array}{l}\vec{\Xi} \\
\dot{0} \\
\dot{v}\end{array}$ & $\begin{array}{l}\bar{\delta} \\
\dot{\theta} \\
\dot{\nabla}\end{array}$ & $\begin{array}{l}\vec{\Xi} \\
\dot{0} \\
\dot{v}\end{array}$ \\
\hline & 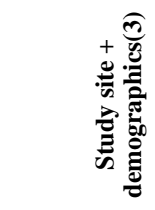 & 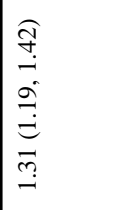 & 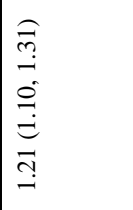 & 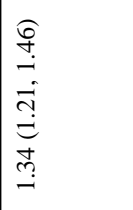 & 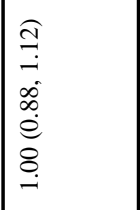 & 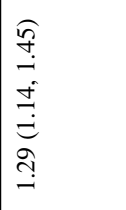 & 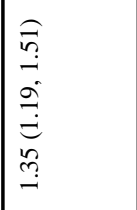 & 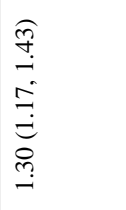 & 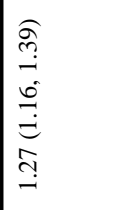 & 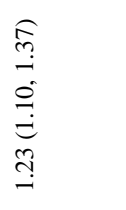 \\
\hline & 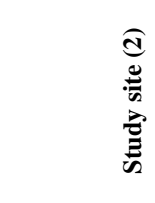 & 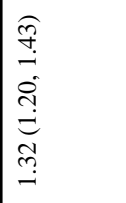 & 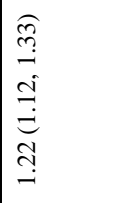 & 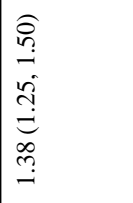 & 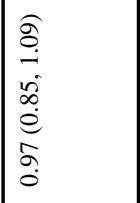 & 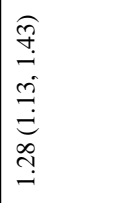 & 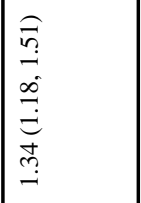 & 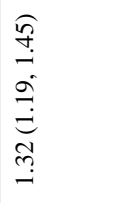 & 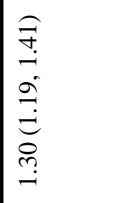 & 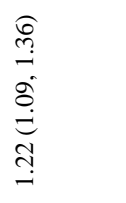 \\
\hline \multirow{3}{*}{ 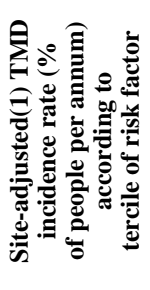 } & ڤัٌ & & & & $\begin{array}{l}n \\
i n \\
n\end{array}$ & $\frac{\infty}{n}$ & if & $\begin{array}{l}5 \\
\dot{0} \\
i\end{array}$ & in & $\stackrel{\leftrightarrow}{\dot{q}}$ \\
\hline & 紊 & 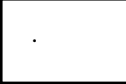 & & & 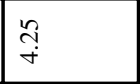 & 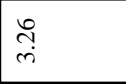 & $\begin{array}{l}\qquad \\
\dot{m} \\
\dot{m}\end{array}$ & in & iे & $\stackrel{\text { f̀ }}{\mathrm{m}}$ \\
\hline & 䓂 & . & 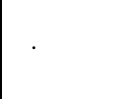 & . & 立 & $\underset{ن}{\stackrel{\leftrightarrow}{c}}$ & $\begin{array}{l}n \\
i \\
i\end{array}$ & ㄹ. & त̂ & $\begin{array}{l}\infty \\
\infty \\
i\end{array}$ \\
\hline \multirow{4}{*}{ 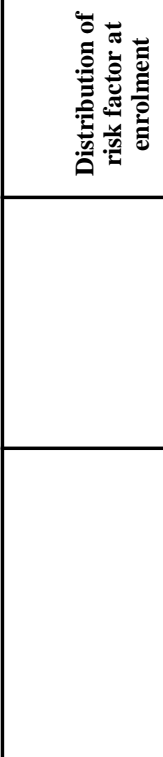 } & 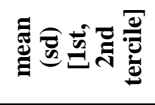 & 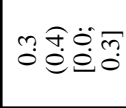 & 두욜 & 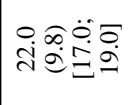 & 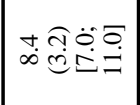 & 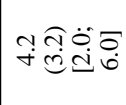 & 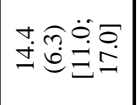 & 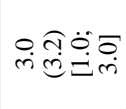 & ن & n⿳亠丷厂犬土 \\
\hline & $=$ & $\frac{0}{i}$ & 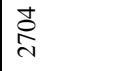 & $\overline{\widehat{C}}$ & 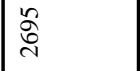 & 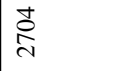 & 灾 & đે & đે & 宮 \\
\hline & 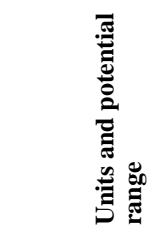 & $\begin{array}{l}\widehat{0} \\
\frac{0}{\tilde{J}} \\
o \\
\pm \\
e\end{array}$ & $\begin{array}{l}\widehat{0} \\
\tilde{J} \\
0 \\
\pm \\
e\end{array}$ & 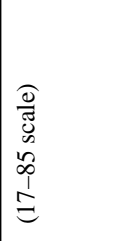 & 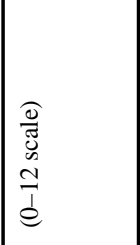 & 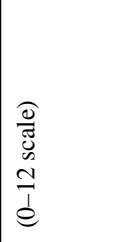 & 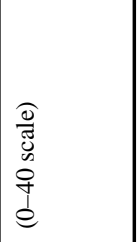 & $\begin{array}{l}\frac{\widehat{D}}{\tilde{J}} \\
0 \\
0 \\
0 \\
e\end{array}$ & $\mid \begin{array}{l}\frac{0}{0} \\
\tilde{n} \\
0 \\
\frac{n}{n} \\
\frac{1}{d}\end{array}$ & $\begin{array}{l}\widehat{0} \\
\tilde{y} \\
0 \\
\infty \\
0 \\
\stackrel{d}{d}\end{array}$ \\
\hline & 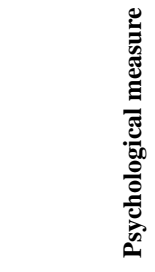 & 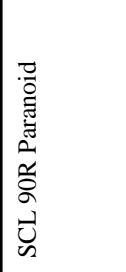 & 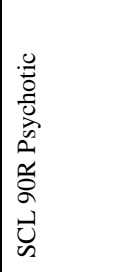 & 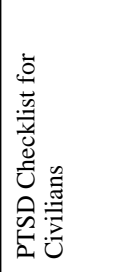 & 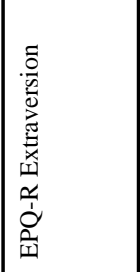 & 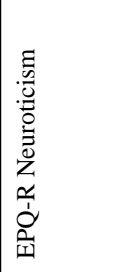 & 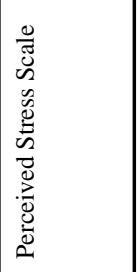 & 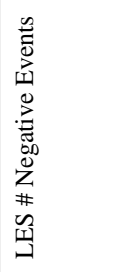 & 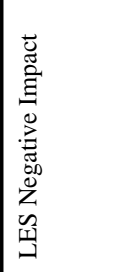 & 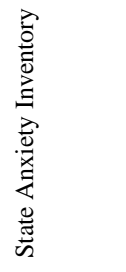 \\
\hline
\end{tabular}




\begin{tabular}{|c|c|c|c|c|c|c|c|c|c|c|}
\hline \multirow{3}{*}{ 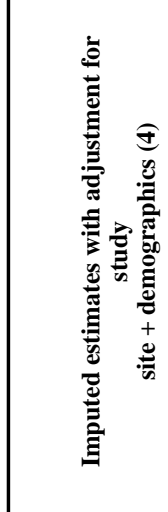 } & 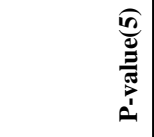 & $\begin{array}{l}\bar{\delta} \\
\dot{Q} \\
\dot{v}\end{array}$ & $\vec{\delta}$ & $\bar{o}$ & 兽 & $\frac{9}{9}$ & 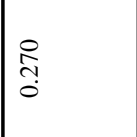 & 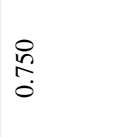 & 离 & 产 \\
\hline & 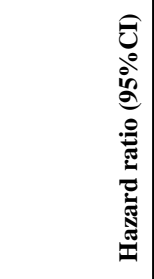 & 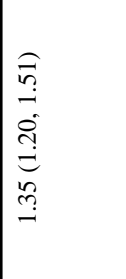 & \begin{tabular}{|l}
$\hat{o}$ \\
0 \\
0 \\
$\hat{i}$ \\
$\hat{0}$ \\
$o$ \\
0 \\
0 \\
0
\end{tabular} & 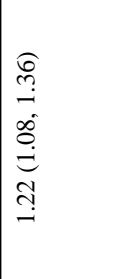 & 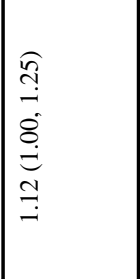 & 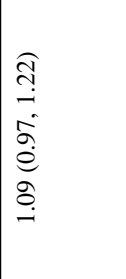 & 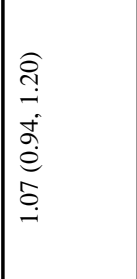 & 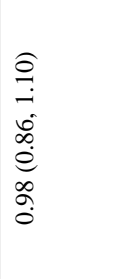 & 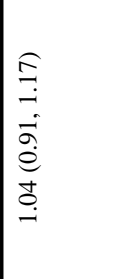 & 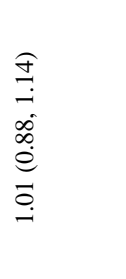 \\
\hline & $=$ & 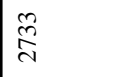 & 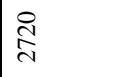 & 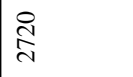 & 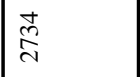 & $\underset{\overbrace{}}{\stackrel{a}{c}}$ & 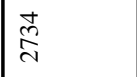 & 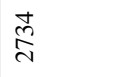 & 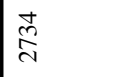 & 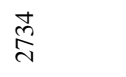 \\
\hline \multirow{3}{*}{ 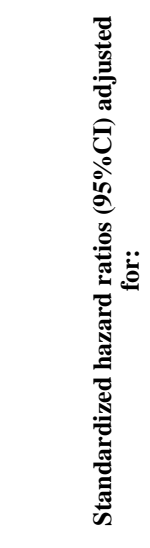 } & 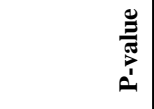 & $\bar{\delta}$ & 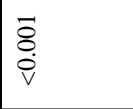 & $\bar{\delta}$ & 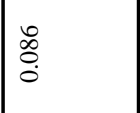 & 荇 & 离 & $\underset{-}{\stackrel{-}{\circ}}$ & 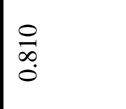 & 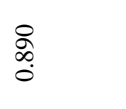 \\
\hline & 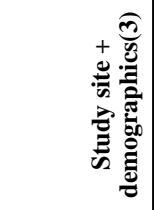 & 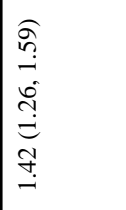 & 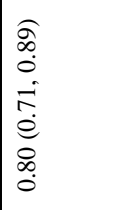 & 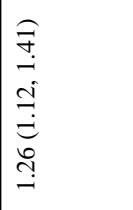 & 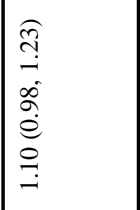 & 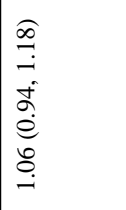 & 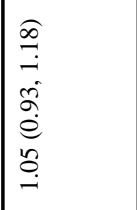 & 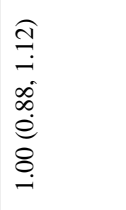 & 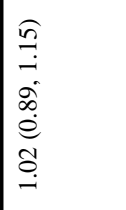 & 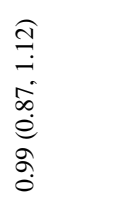 \\
\hline & 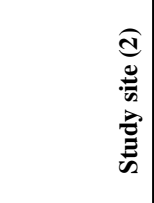 & 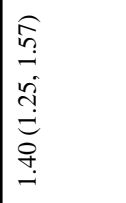 & 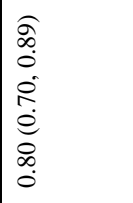 & 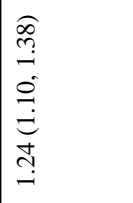 & 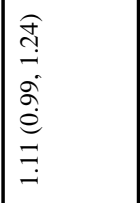 & 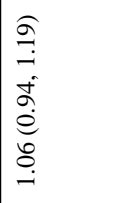 & 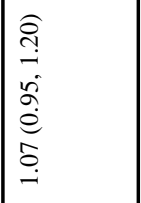 & 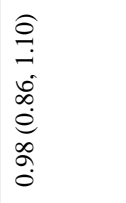 & 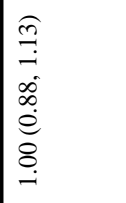 & 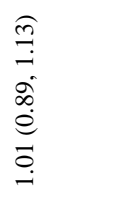 \\
\hline \multirow{3}{*}{ 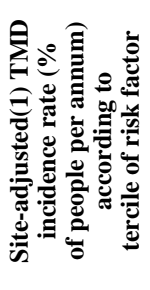 } & 产 & $\stackrel{n}{n}$ & $\stackrel{\sim}{\sim}$ & 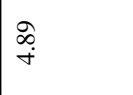 & $\bar{m}$ & & 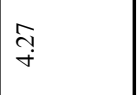 & $\hat{n}$ & & $\overrightarrow{\stackrel{T}{+}}$ \\
\hline & 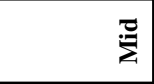 & 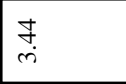 & m & $\begin{array}{l}\bar{n} \\
m\end{array}$ & m & & 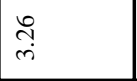 & $\hat{0}$ & & $\underset{\tilde{r}}{\tilde{r}}$ \\
\hline & 䓂 & ì & $\bar{F}$ & $\stackrel{\infty}{\circ}$ & $\stackrel{\infty}{i}$ & . & 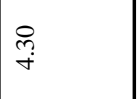 & बे & & 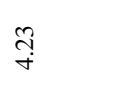 \\
\hline \multirow{4}{*}{ 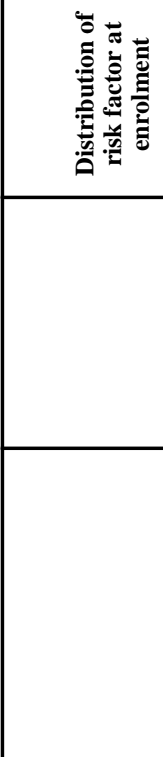 } & 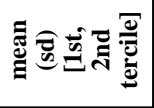 & 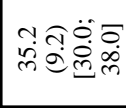 & 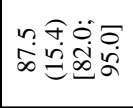 & 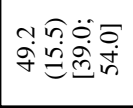 & 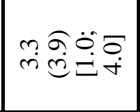 & ن & 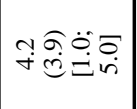 & 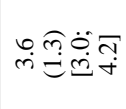 & 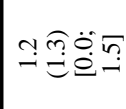 & 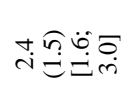 \\
\hline & $=$ & 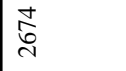 & 葛 & 帒 & $\underset{⿱}{2}$ & 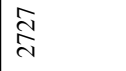 & הิ & $\frac{n}{i}$ & 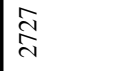 & $\frac{n}{a}$ \\
\hline & 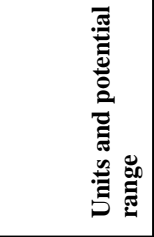 & 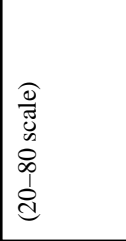 & 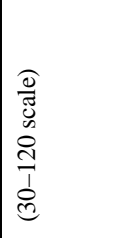 & 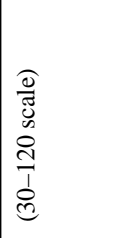 & 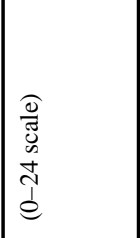 & 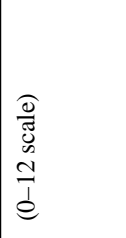 & 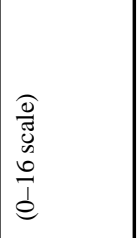 & $\begin{array}{l}\widehat{0} \\
\frac{0}{\tilde{J}} \\
0 \\
0 \\
0 \\
0\end{array}$ & \begin{tabular}{|l}
0 \\
$\frac{0}{\tilde{J}}$ \\
0 \\
0 \\
0 \\
0
\end{tabular} & 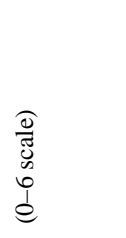 \\
\hline & 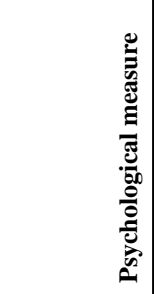 & 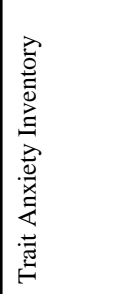 & 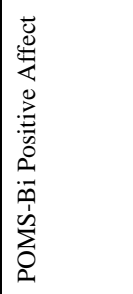 & 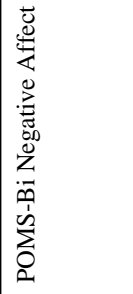 & 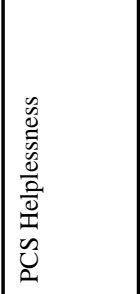 & 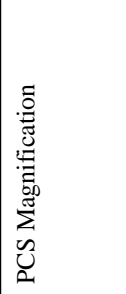 & 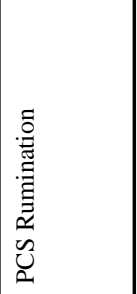 & 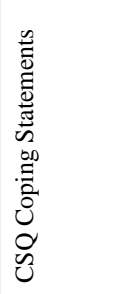 & 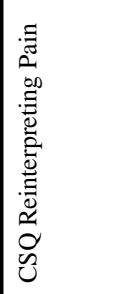 & 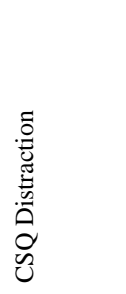 \\
\hline
\end{tabular}




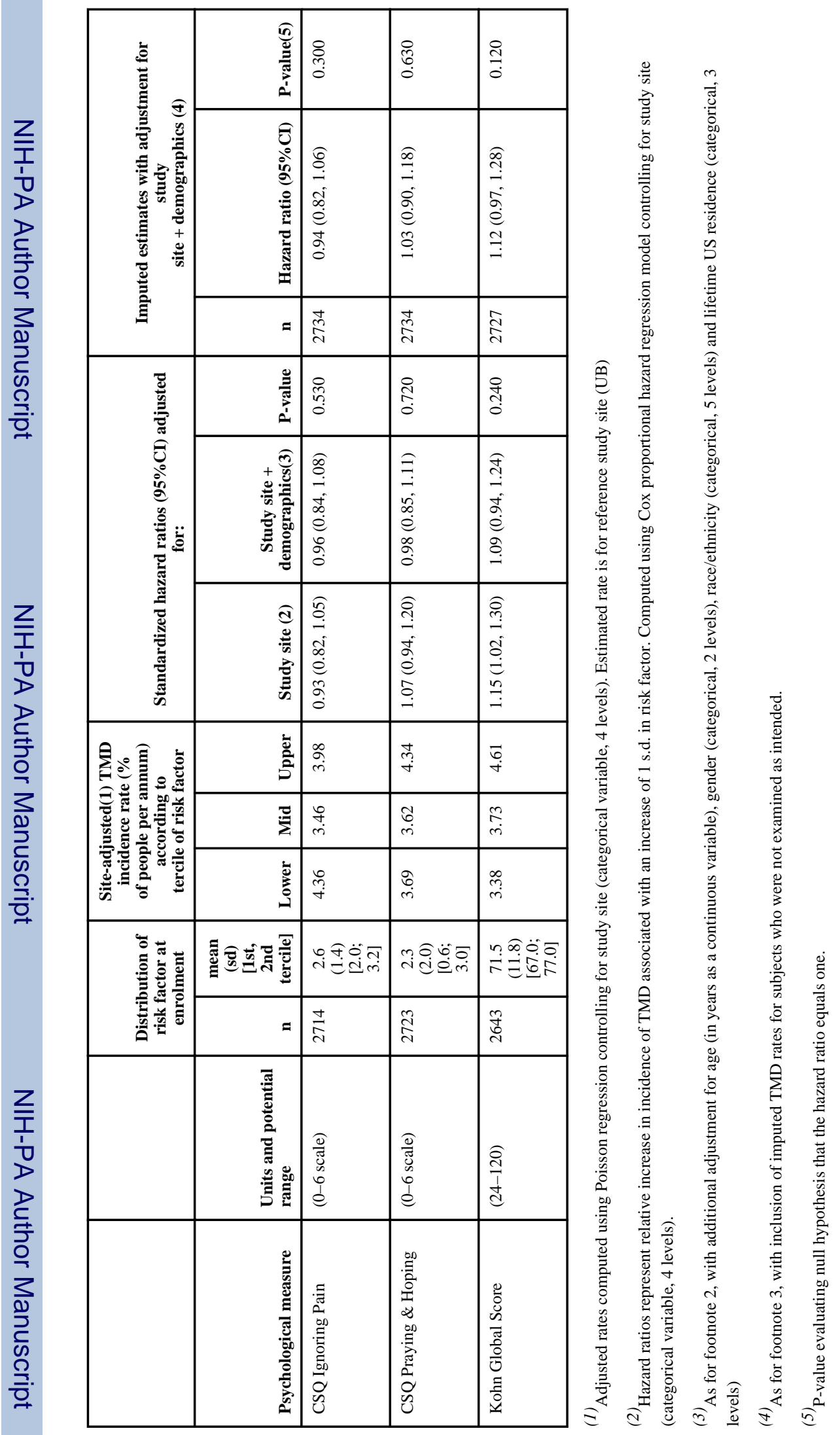

$J$ Pain. Author manuscript; available in PMC 2014 December 01. 
Table 2

Component loadings for Principal Component Analysis (PCA) model

\begin{tabular}{|c|c|c|c|c|}
\hline & Component 1 & Component 2 & Component 3 & Component 4 \\
\hline KOHN Global Score & -0.16 & 0.23 & 0.48 & -0.28 \\
\hline PILL Global Score & 0.42 & 0.06 & 0.11 & 0.07 \\
\hline POMS-Bi Positive Affect & 0.15 & -0.89 & 0.09 & 0.05 \\
\hline POMS-Bi Negative Affect & 0.21 & 0.64 & -0.05 & 0.07 \\
\hline Perceived Stress Scale & 0.08 & 0.72 & 0.08 & 0.01 \\
\hline SCL 90R Depression & 0.75 & 0.22 & 0.01 & -0.01 \\
\hline SCL 90R Somatization & 0.79 & 0.03 & 0.02 & 0.03 \\
\hline SCL 90R Anxiety & 0.92 & -0.01 & -0.01 & -0.03 \\
\hline SCL 90R Obsessive Compulsive & 0.80 & 0.11 & -0.03 & 0.06 \\
\hline SCL 90R Hostility & 0.82 & -0.01 & -0.03 & -0.04 \\
\hline SCL 90R Phobia & 0.85 & -0.13 & 0.02 & -0.06 \\
\hline SCL 90R Paranoid & 0.82 & -0.03 & 0.02 & 0.03 \\
\hline SCL 90R Psychotic & 0.86 & -0.01 & 0.02 & 0.00 \\
\hline CSQ Distraction & -0.16 & 0.01 & 0.35 & 0.65 \\
\hline CSQ IgnoringPain & 0.06 & 0.02 & -0.33 & 0.81 \\
\hline CSQ Distancing & -0.03 & 0.12 & 0.03 & 0.72 \\
\hline CSQ Coping & 0.04 & -0.10 & -0.01 & 0.80 \\
\hline CSQ Praying & -0.10 & -0.08 & 0.57 & 0.27 \\
\hline State Anxiety Inventory & 0.08 & 0.81 & -0.09 & 0.00 \\
\hline Trait Anxiety Inventory & 0.12 & 0.78 & 0.05 & 0.01 \\
\hline PCS Rumination & 0.01 & -0.06 & 0.89 & -0.07 \\
\hline PCS Magnification & 0.06 & -0.01 & 0.79 & 0.01 \\
\hline PCS Helplessness & 0.06 & 0.01 & 0.84 & -0.06 \\
\hline EPQ-R Extraversion & 0.14 & -0.56 & 0.11 & -0.03 \\
\hline EPQ-R Neuroticism & 0.11 & 0.56 & 0.19 & -0.01 \\
\hline PTSD Checklist for Civilians & 0.57 & -0.06 & 0.18 & -0.01 \\
\hline Cumulative Variance & 0.25 & 0.40 & 0.51 & 0.60 \\
\hline
\end{tabular}




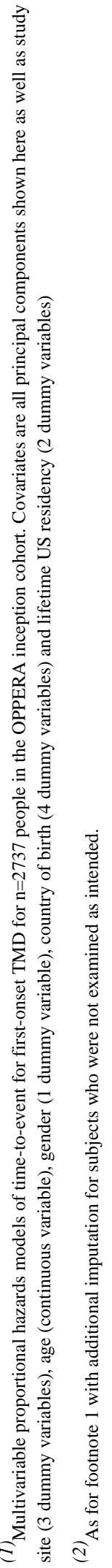

J Pain. Author manuscript; available in PMC 2014 December 01. 